\title{
Optimal management of bone metastases in breast cancer patients
}

\author{
This article was published in the following Dove Press journal: \\ Breast Cancer: Targets and Therapy \\ 29 April 2011 \\ Number of times this article has been viewed
}

\section{MH Wong \\ N Pavlakis}

Department of Medical Oncology, Royal North Shore Hospital, Sydney, NSW, Australia
Correspondence: Matthew H Wong Department of Medical Oncology,

Building 5I, Royal North Shore Hospital, Pacific Highway, St. Leonards,

NSW, Australia 2065

$\mathrm{Tel}+61299265020$

Fax +6I 299064150

Email matthewhwong@uni.sydney.edu.au
Abstract: Bone metastasis in breast cancer is a significant clinical problem. It not only indicates incurable disease with a guarded prognosis, but is also associated with skeletal-related morbidities including bone pain, pathological fractures, spinal cord compression, and hypercalcemia. In recent years, the mechanism of bone metastasis has been further elucidated. Bone metastasis involves a vicious cycle of close interaction between the tumor and the bone microenvironment. In patients with bone metastases, the goal of management is to prevent further skeletal-related events, manage complications, reduce bone pain, and improve quality of life. Bisphosphonates are a proven therapy for the above indications. Recently, a drug of a different class, the RANK ligand antibody, denosumab, has been shown to reduce skeletal-related events more than the bisphosphonate, zoledronic acid. Other strategies of clinical value may include surgery, radiotherapy, radiopharmaceuticals, and, of course, effective systemic therapy. In early breast cancer, bisphosphonates may have an antitumor effect and prevent both bone and non-bone metastases. Whilst two important Phase III trials with conflicting results have led to controversy in this topic, final results from these and other key Phase III trials must still be awaited before a firm conclusion can be drawn about the use of bisphosphonates in this setting. Advances in bone markers, predictive biomarkers, multi-imaging modalities, and the introduction of novel agents have ushered in a new era of proactive management for bone metastases in breast cancer.

Keywords: breast cancer, bone metastases, bisphosphonates, denosumab, biomarkers, optimal management

\section{Background}

Bone is the most common site of recurrence in metastatic breast cancer. Before the era of bisphosphonates, the incidence of bone as the site of metastasis in metastatic breast cancer was as high as $65 \%-75 \%,,^{1,2}$ with a mean skeletal morbidity rate of $2.2-4.0$ events per year. ${ }^{3}$ In patients with operable disease, the cumulative incidence of bone metastases was $8 \%$ at two years and $27 \%$ at 10 years. In early breast cancer, the presence of high-risk features, such as age $<35$ years, tumor size $>2 \mathrm{~cm}$, more than four lymph nodes involved, and estrogen receptor-negative status, further increases the risk of developing bone metastases, with nodal disease showing the highest cumulative incidence of $15 \%$ at two years and $41 \%$ at 10 years. ${ }^{4}$ Bone-only metastases have a better outcome than visceral metastases, with a median survival of 20 months after first bone relapse compared with three months after first liver recurrence. ${ }^{5}$ However, the morbidity associated with bone metastases cannot be underestimated. More than $50 \%$ of these patients develop skeletal-related events, and this necessitates radiotherapy to bone in $41 \%$ and surgical intervention in $10 \% .{ }^{6}$ Given the enormous burden that 
skeletal-related events have on breast cancer patients and our society, there has been much research on the pathophysiology, prevention, and management of bone metastases in the last 20 years. This paper aims to summarize the key issues in this area.

\section{Pathophysiology of breast cancer bone metastases \\ Normal bone physiology}

Normal bone formation is a coordinated dynamic process of active bone production by osteoblasts and bone remodeling by osteoclasts. Osteoblasts arise from mesenchymal stem cells after stimulation by transcription factor core-binding factor alpha-1..$^{7}$ There are a variety of local growth factors, eg, transforming growth factor-beta (TGF- $\beta$ ), insulin growth factor (IGF), bone morphogenic protein, and systemic factors (platelet-derived growth factor, prostaglandins, and parathyroid hormone) that stimulate osteoblasts to differentiate into mature osteocytes, producing alkaline phosphatase, osteocalcin, and calcified bone matrix. ${ }^{8}$ Recent research suggests that Wnt/ $\beta$-catenin is a major regulator of osteoblastogenesis, such that antagonism of this signaling pathway (eg, by Dickkopf-1) has been implicated in osteopenia in animal models. ${ }^{9}$ Osteoclasts, on the other hand, arise from monocyte precursor cells with the major role of bone resorption by expressing high concentrations of cathepsin $\mathrm{K}$ on collagen type 1 in the bone matrix. ${ }^{8}$ While osteoclasts are also stimulated by local factors within the bone microenvironment, such as interleukin-6, interleukin-1, prostaglandins, and colony-stimulating factors from osteoblasts, the key factor for osteoclast production is the receptor activator of nuclear factor (NF)- $\kappa \mathrm{B}$ ligand (RANK-L). ${ }^{8}$ Normally, osteoblasts, stromal cells, and, to a lesser extent, activated T cells release RANK-L upon stimulation by osteotrophic factors, such as parathyroid hormone, 1,25-dihydroxyvitamin $\mathrm{D}_{3}$, and thyroxine. ${ }^{9}$ RANK-L binds to RANK on the surface of osteoclasts and activates the transcription factor, NF- $\kappa \mathrm{B}$, which is essential for the generation and survival of the osteoclast. ${ }^{7}$ To maintain this equilibrium, osteoprotegerin acts as the decoy receptor for RANK-L and inhibits osteoclast function and differentiation. ${ }^{8,10}$ Recently, tumor necrosis factor (TNF)related apoptosis-inducing ligand was found to be the second ligand of osteoprotegerin. TNF-related apoptosis-inducing ligand normally initiates cell apoptosis by activating caspase receptors. Binding of TNF-related apoptosis-inducing ligand to osteoprotegerin may paradoxically enhance cell survival. ${ }^{11}$ Whilst RANK-L/RANK is one crucial pathway that maintains the homeostasis of bone metabolism, there are other ways by which osteoblasts interact with osteoclasts to achieve this balance. One nonredundant alternate pathway involves membrane bound-colony stimulating factor-1. Membrane bound-colony stimulating factor- 1 is produced by osteoblasts and also acts on the target receptor expressed by osteoclast progenitors. ${ }^{7}$ Membrane bound-colony stimulating factor-1 is a survival factor for osteoclasts, and also appears to induce their differentiation. ${ }^{12}$ Thus, osteoblastogenesis and osteoclastogenesis are normally tightly regulated by paracrine factors within the bone microenvironment, as well as by hormonal factors, and it is likely that the levels of these factors, such as the RANKL/osteoprotegerin/TNF-related apoptosis-inducing ligand ratio, are crucial to normal bone metabolism.

\section{Organized and multistep process of tumor migration}

Bone metastasis is not a random event, but an organized and multistep process that involves tumor intravasation, survival of cells in the blood circulatory system, extravasation into the surrounding tissue, initiation and maintaining growth, and vascularization/angiogenesis. ${ }^{13}$ To execute this complex operation, there has to be an interplay of multiple gene mutations, protein expression, and signaling of aberrant pathways. In a landmark study, a multigenic examination of breast cancer bone metastases identified key gene expression signature involved in this process early. These genes include C-X-C chemokine receptor type 4 (CXCR4), fibroblast growth factor 5, connective tissue-derived growth factor, interleukin-11, matrix metalloproteinase (MMP)-1, folistatin, ADAMTS1, and proteoglycan-1, all of which are overexpressed by at least four-fold when compared with the same cell line that has not metastasized to bone. ${ }^{14}$ Whilst much remains to be learnt about this diverse group of genes, it is understood that they encode for proteins with specific functions (eg, connective tissue growth factor and fibroblast growth factor 5 in angiogenesis, and interleukin-1 and osteopontin in osteolysis) that cooperatively promote successful cancer metastasis. ${ }^{14}$

Two of the many classes of proteins crucial for metastatic breast cancer in transit to bone are MMP and chemokines. MMP is a superfamily of at least 28 zinc-dependent proteinases that disintegrate the extracellular matrix. ${ }^{15} \mathrm{MMP}-2$ is the most studied in metastatic breast cancer. It cooperates with adhesion molecules, such as E-cadherin, resulting in invasion of the basement membrane. ${ }^{15} \mathrm{MMP}-2$ is also significantly increased in patients with HER2/neu gene-amplified tumors, suggesting MMP-2 as one signaling pathway for this 
aggressive tumor phenotype. ${ }^{15}$ Both MMP-2 and MMP-9 are associated with a poor prognosis in breast cancer when found at high levels. ${ }^{16,17}$ Chemokines, on the other hand, are small molecular cytokines essential for inducing chronic inflammation, tumor angiogenesis, and homing of tumor cells to target end-organs. ${ }^{18}$ Among the chemokine family, CXCR4 and C-C chemokine receptor type 7 are particularly important for breast cancer migrating to bone. CXCR4 and C-C chemokine receptor type 7 are receptors normally found on lymphocytes and stem cells, which enable these cells to transport high levels of their respective ligands, CXCL12 (also known as stromal cell-derived factor-1) and CCL21, to the organs, namely the liver, lung, lymph nodes, adrenal glands, and bone marrow. ${ }^{18-20}$ In the same way, breast cancer cells also adopt this system by overexpressing CXCR4 and CCR7 receptors on their cell surfaces, thereby allowing them to "home in" on these end organs for metastasis. ${ }^{20}$ In fact, the CXCR4/SDF and CCR7/CCL21 axes are commonly manipulated by breast cancer bone metastases. CXCR4 receptor is expressed in $67 \%$ of breast cancer bone metastases with immunohistochemistry compared with $26 \%$ of nonbone metastases, whereas CCR7 is expressed exclusively in breast cancer bone metastases $(27 \%$ versus $0 \%){ }^{21}$ Moreover, CXCR4 activation results in stimulation of the downstream mitogenic pathway (ERK1/2 and p38 mitogen-activated protein kinase [MAPK]) and contributes to estrogen independence of the tumor. ${ }^{22}$ The connection between CXCR4, breast cancer proliferation, and bone metastasis has made CXCR4 an attractive therapeutic target. Multiple preclinical studies have now demonstrated the efficacy of CXCR4 antagonists in inhibiting bone metastases of breast cancer, ${ }^{23,24}$ and a recent Phase I/II clinical trial has also demonstrated preliminary signs of efficacy. ${ }^{25}$

Another pair of chemokine receptors exploited by breast cancer cells is CCR2 and CCR5, with their respective ligands, CCL-2 (also known as monocyte chemotactic protein-1 [MCP-1]) and CCL5, also known as RANTES ("regulated upon activation, normal T cell expressed, and secreted"). MCP-1 and RANTES are highly expressed in breast cancer cells, especially in the more advanced stages. ${ }^{26}$ They are responsible for recruiting deleterious tumor-associated macrophages, promote tumor-bone interactions, and angiogenesis (mainly via MCP-1). ${ }^{26}$ In addition, both bone marrowderived and local stem cells can produce CCL5 in the bone microenvironment, further adding fuel to flame the effect of bone metastases. ${ }^{27,28}$ In short, cancer metastasis to bone is a structured and coordinated process that requires multiple steps, gene expression, and protein interactions. Therefore, it is likely that multiple pathways need to be targeted to reduce the occurrence of bone metastasis.

\section{"Seed and soil" model of tumor engraftment}

Although hematogenous dissemination and extravasation of cancer cells to secondary sites are efficient processes, the initiation and persistence of growth is relatively inefficient. ${ }^{13}$ Hence, optimal conditions for tumor cells to resettle are paramount after they have lodged in the bone microenvironment. Bone certainly has some unique qualities that favor tumor engraftment. Firstly, bone is a highly vascular organ. The axial skeleton contains large amounts of red marrow, which is demonstrated to have high blood flow. ${ }^{29}$ Secondly, bone susceptible to metastases is dysregulated in its acidity, intramedullary oxygen, and extracellular calcium levels. Thirdly, bone also harbors an abundance of growth factors, including TGF- $\beta$, IGF, hypoxic-inducing factor, interleukins, and chemokines, all of which are vital to cancer cell survival and proliferation. In essence, both the tumor and the host microenvironment contribute to the successful tumor engraftment from primary site to bone. Over 100 years ago, Paget described this phenomenon as the "seed and soil" model, where "the seeds (tumor) can only live and grow if they fall on congenial soil (an optimal microenvironment)". ${ }^{30}$ Recently, Psaila and Lyden further expand on Paget's original concept, and postulate the "metastatic niche" model, where the primary tumor prepares a "premetastatic niche" (the eventual site of bone metastases) by secreting a plethora of growth factors, such as vascular endothelial growth factor, placental growth factor, TGF- $\beta, \mathrm{S} 100$ chemokine, and serum amyloid A3, even before tumor migration. ${ }^{31}$ Once tumor has engrafted on the "metastatic niche", a continuing supply of growth factors, particularly vascular endothelial growth factor and placental growth factor, from the microenvironment, loss of death signals, and recruitment of endothelial progenitor cells, are necessary for the evolution of a tumor population from micrometastasis to macrometastasis. ${ }^{31}$ Thus, the symbiotic relationship between tumor and bone is pivotal to the settlement of metastases in new distant sites.

\section{Osteolytic and osteoblastic metastases in bone}

In cancer with bone metastases, the delicate balance between bone formation and resorption is disrupted. In osteolytic lesions, the bone resorption rate exceeds that of bone formation, whereas in osteoblastic lesions, the bone formation rate is faster. However, this occurs at the cost of quality of bone 
formation and organization, so the bone is flawed and fragile. Traditionally, breast cancer was recognized as the prototypic osteolytic tumor. However, this is a gross oversimplification. Only about $48 \%$ of bone metastases from breast cancer are purely osteolytic, with $38 \%$ being mixed osteoblastic and osteolytic, and $13 \%$ being purely osteoblastic. ${ }^{32}$ In fact, in bone metastases, both lytic and blastic processes are often accelerated. Histologically, there is evidence of resorption cavities even within sclerotic lesions. Biochemically, it has been observed that specific bone resorption markers are increased in bone metastases, irrespective of lytic or blastic radiological appearance. ${ }^{33}$ Therefore, osteolytic and osteoblastic changes are not opposing processes, but rather two distinct pathologies that frequently coexist.

In the osteolytic tumor, tumor cells secrete parathyroid hormone-related protein and other factors, such as interleukins, prostaglandin E, TNF- $\beta$, and IGF-1, all of which are potent stimulators of osteoclastogenesis ${ }^{8,9}$ (see Figure 1). Parathyroid hormone-related protein is a crucial factor in breast cancer metastasis, with expression of $92 \%$ of breast cancer metastases in bone, compared with $60 \%$ of primary breast cancer, and only $17 \%$ of metastases at non-bone sites. ${ }^{34}$ Parathyroid hormone-related protein mediates its effect through the receptors on osteoblasts, which respond by upregulating RANK-L and macrophage-colony stimulating factor. ${ }^{35}$ This is accompanied by a downregulation of osteoprotegerin, resulting in a tilting of the RANK-L/ osteoprotegerin ratio in favor of osteoclastogenesis. ${ }^{36}$ Indeed, breast cancer patients with bone metastases are more likely to express RANK in tumor cells and osteoclasts, and RANK-L in stromal cells and osteoblasts, compared with patients who do not have bone metastases or have been on bisphosphonates. ${ }^{37}$ Once osteoclasts are activated, they produce TGF- $\beta$, IGF-1, and other growth factors. TGF- $\beta$ has a particularly significant role in tumorigenesis, because it is a potent stimulator of parathyroid hormone-related protein via Smad and the p38 MAPK signaling pathway. ${ }^{38}$ In addition, TGF- $\beta$ activates signaling pathways similar to those of hypoxia by upregulating the CXCR4 and vascular endothelial growth factor gene pathway via hypoxic-inducing factor, to promote the feedforward metastatic cycle. ${ }^{39,40}$ In this way, the loop of bone

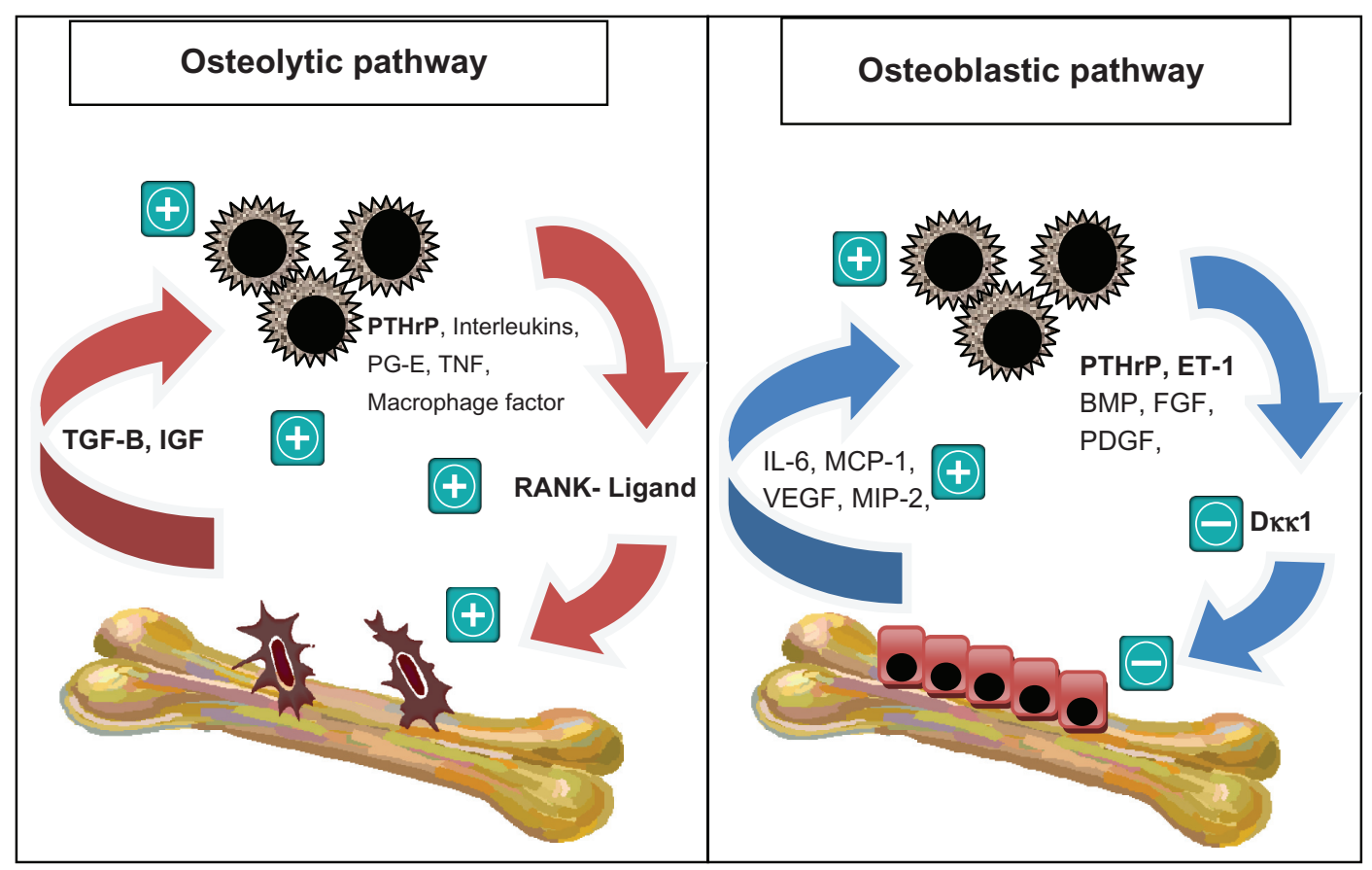

Figure I The vicious cycle of bone metastases in the osteoblastic pathway, in which tumor cells secrete other factors (interleukins, prostaglandin E, tumor necrosis factor, and macrophage-stimulating factor). Parathyroid hormone-related protein induces osteoclastogenesis by upregulating the RANK ligand. The activated osteoclasts in turn produce transforming growth factor-beta and insulin growth factor which promote cancer cell growth. In the osteoblastic vicious cycle, breast cancer cells produce osteoblast-stimulating factors, such as bone morphogenic protein, fibroblast growth factor, and platelet-derived growth factor. Parathyroid hormone-related protein is also overexpressed. It activates endothelin-I, which downregulates Dickkopf-I, a negative regulator of osteoblastogenesis. The activated osteoblasts in turn produce factors including interleukin-6, monocyte chemotactic protein-I, vascular endothelial growth factor, MIP-2, which facilitate breast cancer cell colonization and survival upon arrival in the bone microenvironment. In reality, there is a complex interplay between the two cycles. 8,9,42,43

Abbreviations: BMP, bone morphogenic protein; IGF, insulin growth factor; PTHrP, parathyroid hormone-related protein; ET-I, endothelin-I; PDGF, platelet-derived growth factor; IL-6, interleukin-6; FGF, fibroblast growth factor; PG-E, prostaglandin E; TNF, tumor necrosis factor; MCP, monocyte chemotactic protein-I; TGF-B, transforming growth factor beta; VEGF, vascular endothelial growth factor. 
destruction is complete, and it becomes a self-perpetuating cycle where the tumor and osteoclasts provide fuel for each other. There is certainly in vivo evidence that parathyroid hormone-related protein and TGF- $\beta$ are crucial players in bone osteolysis..$^{38,41}$ Targeted treatment, such as SD-208, a TGF- $\beta$ receptor kinase I inhibitor, is being developed based on these models. ${ }^{42}$

The osteoblastic pathway is less well studied, with research mostly focused on prostate cancer. Tumors produce many factors that stimulate osteoblasts, including endothelin-1, bone morphogenic protein, fibroblast growth factor, and platelet-derived growth factor. ${ }^{43}$ The key factor appears to be endothelin-1 which, upon binding to the endothelin A receptor, suppresses Dickkopf-1, a negative regulator of the Wnt pathway. ${ }^{9}$ Studies have demonstrated an inverse relationship between expression of Dickkopf-1 and osteoblastogenesis, which is independent of osteoclastogenesis. ${ }^{44,45}$ Parathyroid hormone-related protein is also paradoxically overexpressed in osteoblastic metastases. The theory is that parathyroid hormone-related protein is cleaved by various proteases, and the resulting $\mathrm{NH}_{2}$-terminal fragments also activate the endothelin A receptor ${ }^{42}$ (see Figure 1). The activated osteoblasts in turn produce factors, including interleukin-6, MCP-1, vascular endothelial growth factor, and MIP-2, which probably facilitate breast cancer cell colonization and survival upon arrival in the bone microenvironment. ${ }^{46}$ There is certainly in vivo evidence supporting a vicious osteoblastic cycle. Treatment with atrasentan, a selective endothelin-1A receptor antagonist (with no intrinsic antitumor properties), decreased osteoblastic metastasis and tumor burden in an animal model, suggesting that osteoblasts and tumor cells are closely linked. ${ }^{47}$ Further studies are required to elucidate this pathway.

In summary, bone metastasis formation involves a vicious cycle between tumor and bone, where one stimulates the other in a perpetual spiral of bone matrix distortion. This certainly occurs in osteolytic metastases, but probably also in osteoblastic metastases. In reality, there is a complex interplay between osteoblastic and osteolytic pathways. This is supported by the observation of $38 \%$ mixed osteolytic/osteoblastic lesions in breast cancer with bone metastases, as well as the evidence that bisphosphonates, which are potent osteoclast inhibitors, are effective in both osteoblastic and osteolytic lesions. Understanding the steps involved in the complex pathophysiology of bone metastases has helped to develop specific drug targets to break this vicious cycle.

\section{Optimal management of bone metastases in metastatic breast cancer}

\section{Preventing skeletal related events from established bone metastases}

Bisphosphonates are an important class of therapeutics in reducing the frequency of skeletal-related events (30\%-40\%) and improving bone pain $(50 \%),{ }^{48}$ as well as being a recognized treatment for malignant hypercalcemia. Bisphosphonates inhibit osteoclasts by inducing apoptosis of osteoclasts, and are therefore potent inhibitors of bone resorption. Once administered, bisphosphonates are rapidly cleared from the circulation and selectively bind to bone surfaces. ${ }^{49,50}$ Simple bisphosphonates, including clodronate, are converted intracellularly into methylene-containing analogs of ATP. This metabolite accumulates within macrophages and osteoclasts and causes direct apoptosis. Nitrogen-containing bisphosphonates, including pamidronate, ibandronate, and zoledronic acid, inhibit farnesyl diphosphate synthase, a rate-limiting enzyme of the mevalonate pathway. Inhibition of farnesyl diphosphate synthase prevents protein prenylation of small GTPases, such as Ras, Rho, and Rab, which are important signaling proteins that regulate cell survival in osteoclasts. ${ }^{51,52}$ In vitro, at higher concentrations, nitrogen-containing bisphosphonates also inhibit osteoblasts, epithelial and endothelial cells, and breast, myeloma, and prostate tumor cells. ${ }^{52}$ This may explain, in part, the antitumor properties of potent nitrogen-containing bisphosphonates, such as zoledronic acid. The potency, structure, and dosage of the bisphosphonates for metastatic breast cancer are shown in Table 1.

Bisphosphonates have been clearly shown to reduce skeletal-related events in metastatic breast cancer. There have been in excess of 30 randomized controlled trials in the last 20 years evaluating clodronate, pamidronate, ibandronate, and zoledronic acid against placebo or against each other. The interpretation of an overall drug class effect by meta-analysis has proved challenging (see Figure 2), and is limited to studies reporting incidence rates. One of the problems has been in the definition of skeletal-related events, an aggregate endpoint, that encompasses complications of new bone metastases, pathological fractures, spinal cord compression, irradiation of or surgery on bone, and development or progression of bone pain. In many of these trials, hypercalcemia was also included in the definition of a skeletal-related event. ${ }^{53}$ Because bisphosphonates are a well proven and highly effective treatment for malignant hypercalcemia, including this in the pooled skeletal-related event endpoint may bias results in favor of 


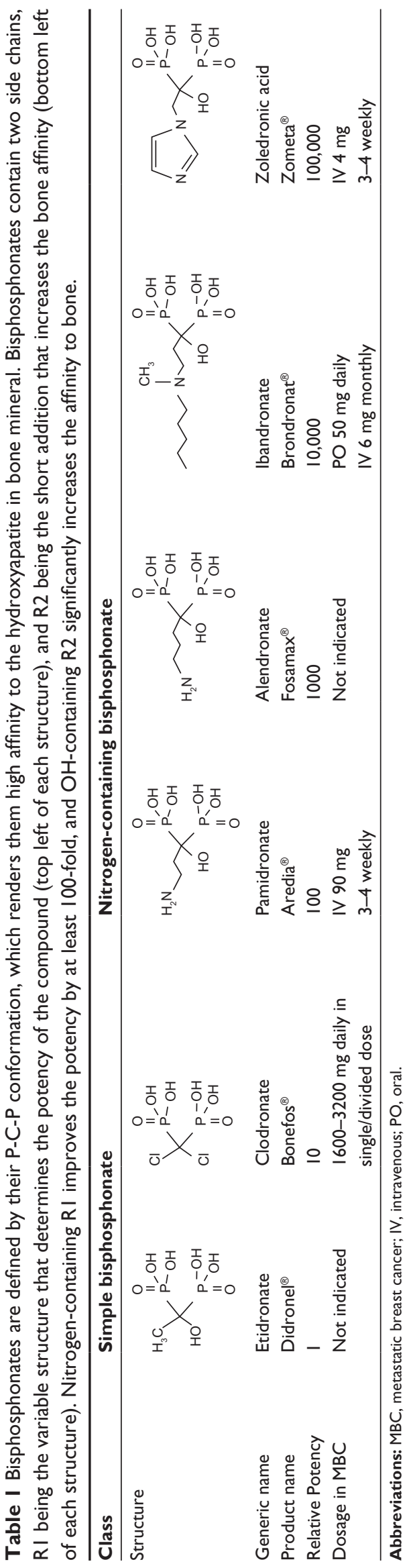

a positive treatment effect. Another problem has been the inconsistency in methodology chosen for reporting skeletalrelated events. Some trials measured skeletal-related events using a surrogate endpoint of skeletal morbidity rate, defined as the mean number of skeletal-related events per year, ${ }^{54,55}$ or as the skeletal morbidity period rate, defined as the number of 12-week periods with new skeletal complications. ${ }^{56,57}$ Skeletal morbidity rate and skeletal morbidity period rate assume a constant event rate per patient in a given time period, and have been criticized because of failure to take into account the timing of events, resulting in unduly narrow confidence intervals (CI) and inflated false positive rates in treatment comparisons. ${ }^{58}$ More sophisticated models, such as the multiple event analyses model, could be used because this accounts for both timing and events. ${ }^{59}$ Given the limitations of these studies, pooled analysis of bisphosphonate trial data has proved an arduous task.

To evaluate the role of bisphosphonates in metastatic breast cancer, data from 18 randomized controlled trials including in excess of 5600 patients were integrated in a Cochrane systematic review and meta-analysis. ${ }^{53}$ For women with advanced breast cancer and clinically evident metastases, bisphosphonates reduced the risk of developing skeletalrelated events (excluding hypercalcemia) by $15 \%$ (95\% CI $0.79-0.91, P<0.00001)$. Bisphosphonates also significantly delayed time to skeletal events by $3-6$ months. However, they did not reduce the incidence of new metastases (hazards ratio [HR] 0.99, 95\% CI 0.67-1.47), nor affect survival in women with locally advanced or metastatic breast cancer (HR 0.99 , 95\% CI 0.93-1.05). Efficacy was demonstrated for both the oral and parenteral routes of administration, with a relative risk (RR) of 0.83 for intravenous bisphosphonate $(95 \%$ CI $0.78-0.89)$ and 0.84 for oral bisphosphonate (95\% CI 0.74-0.86). Individual drug effects on the RR of a skeletalrelated event were 0.59 (intravenous zoledronic acid), 0.77 (intravenous pamidronate), 0.82 (intravenous ibandronate), 0.84 (oral clodronate), and 0.86 (oral ibandronate) compared with placebo (see Figure 2).

So which bisphosphonate is better? Rosen et al published a multicenter, double-blind, randomized, controlled trial with a head-to-head comparison between $4 \mathrm{mg}$ or $8 \mathrm{mg}$ zoledronic acid and $90 \mathrm{mg}$ pamidronate every 3-4 weeks for up to two years in metastatic breast cancer patients with bone metastases $(\mathrm{n}=1130) .{ }^{60}$ Following a protocol modification due to concerns about renal toxicity with $8 \mathrm{mg}$ zoledronic acid, the trial demonstrated noninferiority of $4 \mathrm{mg}$ zoledronic acid to $90 \mathrm{mg}$ pamidronate, with the on-study skeletal-related event rate (excluding hypercalcemia) being $43 \%$ for zoledronic acid 
Review: Bisphosphonates for breast cancer

Comparison: I any Bisphosphonate $v$ control

Outcome: 4 Overall risk of skeletal events in $\mathrm{ABC}$ by individual drug at recommended dosing

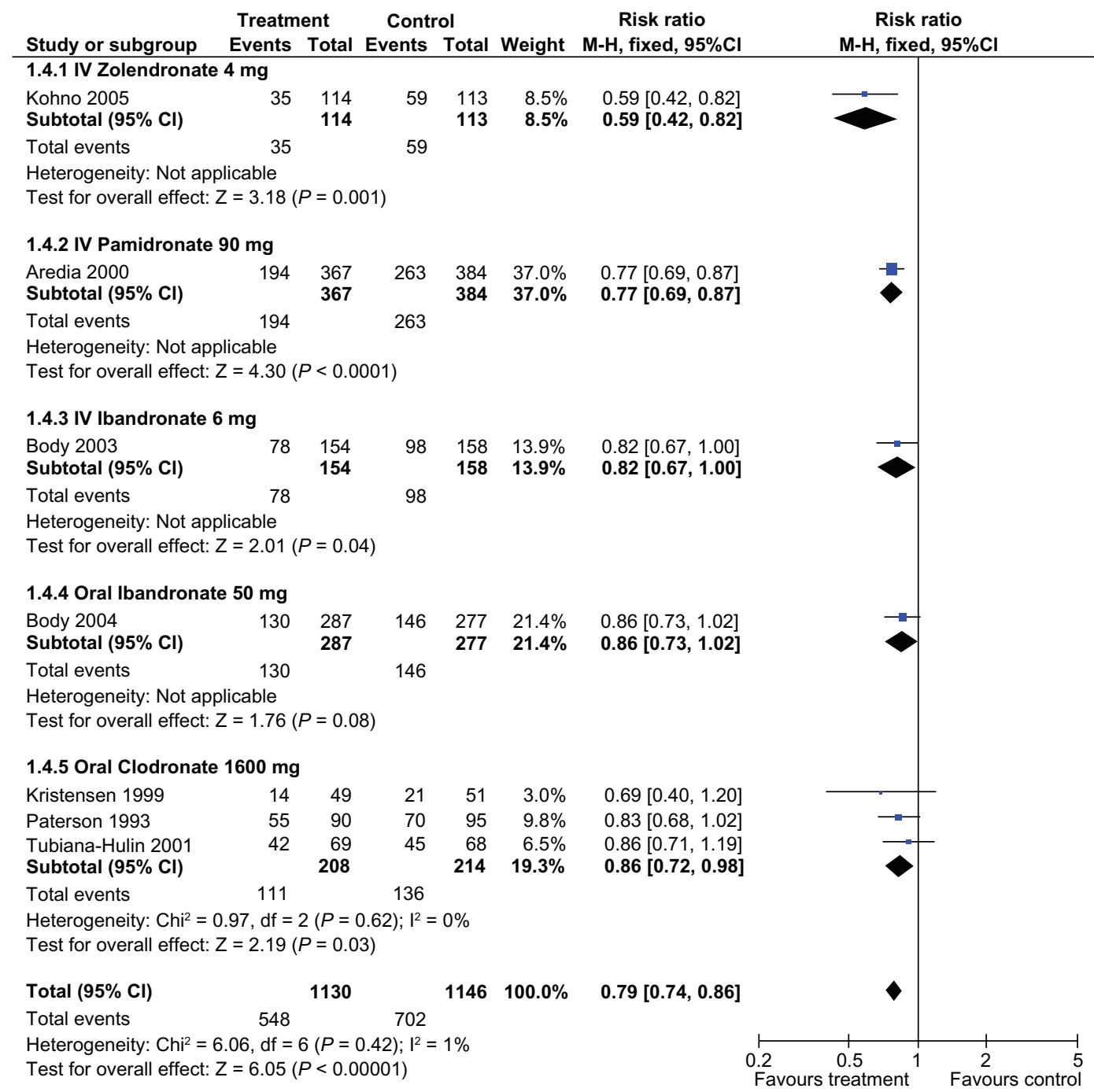

Figure 2 Subgroup analysis of each bisphosphonate versus controls in reduction of the overall risk of skeletal-related events. All bisphosphonates decreased the overall risk of skeletal-related events, with a risk reduction of $41 \%$ for intravenous zoledronic acid, $23 \%$ for intravenous pamidronate, $18 \%$ for intravenous ibandronate, $14 \%$ for oral ibandronate, $16 \%$ for oral clodronate, resulting in a mean $21 \%$ risk reduction for all bisphosphonates combined. Note that in each subgroup the included trials are different. Therefore, conclusions about the relative efficacy between bisphosphonates cannot be extrapolated from this table. Note also that two intravenous pamidronate studies (Conte, Hultborn) were excluded from this subgroup analysis because they used less than the standard recommended dose of 90 mg. Reproduced with permission from (c) Cochrane Collaboration. ${ }^{53}$

and $45 \%$ for pamidronate. Using the multiple-event analysis model, this difference was shown to be significant for zoledronic acid (HR 0.801, $P=0.037$ ). Within the lytic metastases subgroup ( $47 \%$ of patients), zoledronic acid yielded a significant prolongation of time to first skeletal-related event (310 versus 174 days, $P=0.013$ ), significant reduction in skeletal morbidity rate (1.2 versus 2.4 events, $P=0.008)$, and a significant reduction in skeletal-related event rate of 30\% $(P=0.010) .{ }^{61}$ Interestingly, the skeletal morbidity rate was significantly lower when zoledronic acid was combined with radiotherapy ( 0.47 versus 0.71 events, $P=0.018)$ or with hormone therapy ( 0.33 versus 0.58 events, $P=0.015)$, suggesting synergism between zoledronic acid and other antitumor therapies in preventing skeletal complications. ${ }^{60}$

Oral ibandronate has also been compared with intravenous zoledronic acid in a randomized Phase III study. Metastatic breast cancer patients with bone metastases were randomized 1:1 to receive oral ibandronate $50 \mathrm{mg}$ daily versus intravenous zoledronic acid $4 \mathrm{mg}$ monthly $(\mathrm{n}=275) .{ }^{62}$ This was a biomarker study, with serum cross-linked C-terminal telopeptide type 1 collagen being the primary endpoint. Both bisphosphonates significantly reduced serum 
cross-linked C-terminal telopeptide type 1 collagen, with a $76 \%$ reduction in the ibandronate arm and a $73 \%$ reduction in the zoledronic acid arm. There was a similar reduction in other bone turnover markers with the two treatments. There were fewer adverse events in the ibandronate arm, with less treatment-related pyrexia ( $0 \%$ versus $16.8 \%)$, influenza-like symptoms $(0.7 \%$ versus $5.1 \%)$, musculoskeletal and connective tissue disorders (11\% versus $20.4 \%$ ), and headaches $(2.2 \%$ versus $11 \%)$. Importantly, there was no evidence of deterioration in renal function in either group. Skeletal-related events were not measured as an endpoint in this study. A Phase III trial comparing zoledronic acid and ibandronate (Zoledronic acid versus oral Ibandronate Comparative Evaluation [ZICE]), with skeletal-related events as the primary endpoint, is underway in the UK and scheduled for completion in 2011. ${ }^{63}$

Current treatment guidelines are summarized in Table 2. Selecting which bisphosphonate to use needs to be individualized, and the decision is likely to be influenced by the additional benefit of some bisphosphonates in reducing bone pain, their convenient administration, toxicity profiles, and drug accessibility (Table 3 ).

When to start a bisphosphonate and when to stop? There is controversy in both areas due to a paucity of data specifically addressing this question. In the exploratory retrospective analysis of the Rosen et al trial of pamidronate versus zoledronic acid, patients who already had one prior skeletalrelated event were found to be at significantly higher risk of developing an on-study skeletal-related event than patients with no prior skeletal-related event, with an HR of $2.08 .{ }^{64}$ This suggests that waiting for a skeletal-related event to occur may be detrimental for patients with bone metastases. As such, both the American Society of Clinical Oncology guidelines and the International Expert Panel guidelines recommend starting bisphosphonates at the first radiographic sign of cancer in bone. ${ }^{65,66}$ As for the duration of bisphosphonate treatment, there are currently few data on the efficacy and safety of bisphosphonates beyond two years. There are certainly some concerns about prolonged use of bisphosphonates, regarding their overall cost-effectiveness, impact on quality of life (particularly with monthly infusions), and the theoretical concept of "frozen bone", where prolonged use of high-dose bisphosphonates in animal models has been found to increase microdamage and decrease bone toughness. ${ }^{67}$ This pathology is thought to be the underlying mechanism of osteonecrosis of the jaw, the risk of which increases with the cumulative dose of bisphosphonate, especially with zoledronic acid and pamidronate. ${ }^{68}$ Currently, the bone tumor

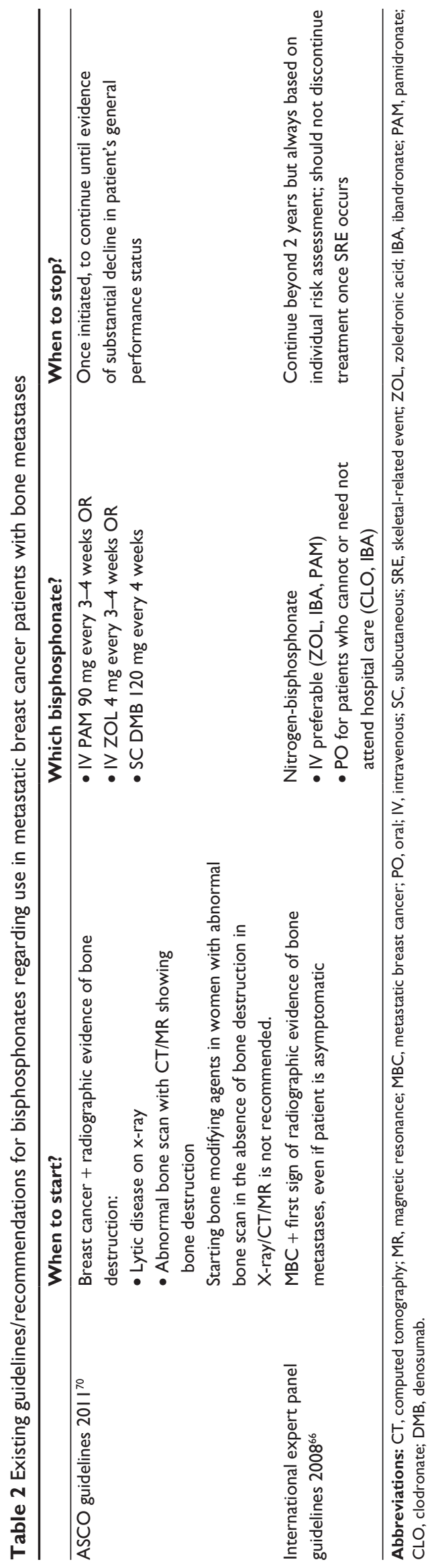




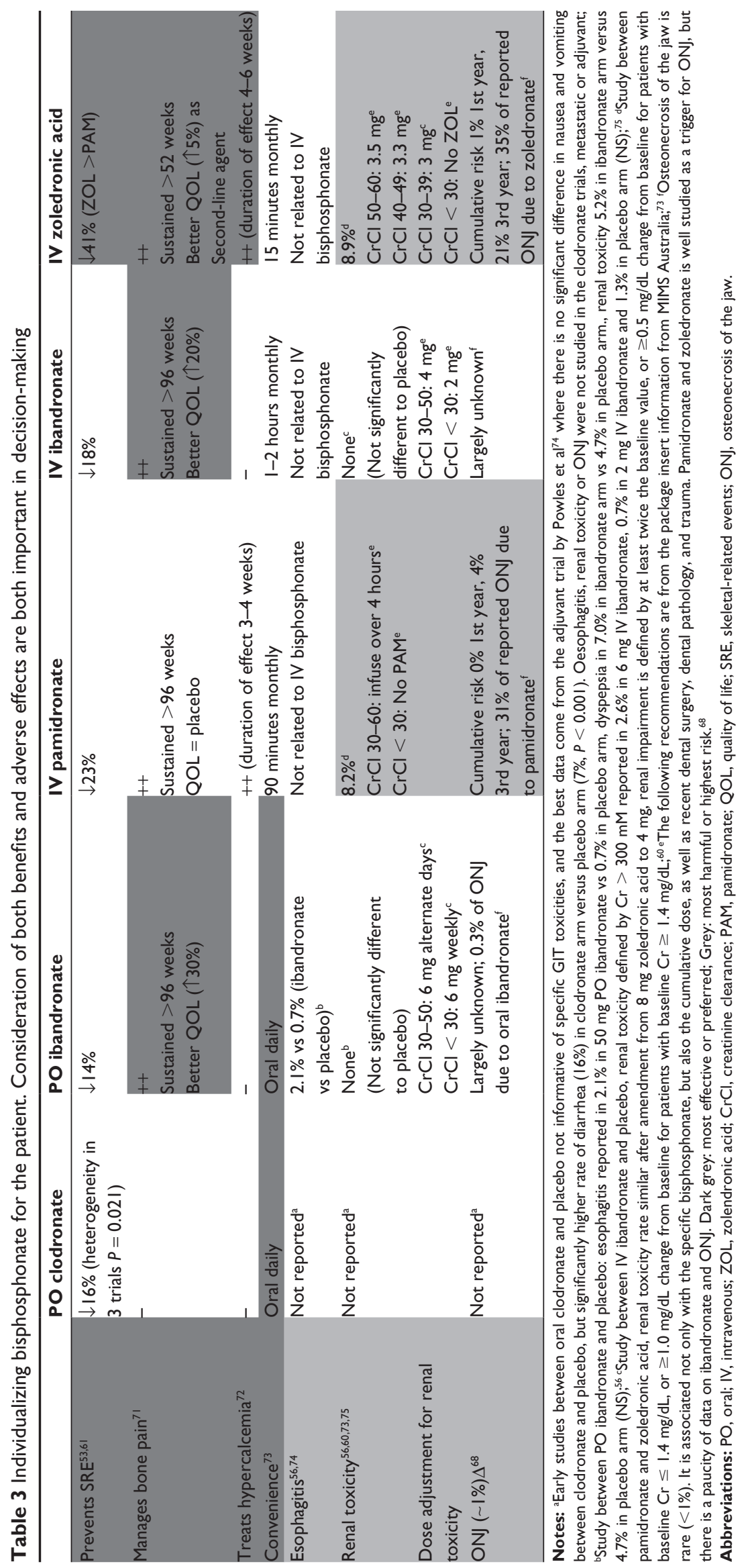


response to therapies is assessed by imaging at the discretion of the treating oncologist every 2-6 months, with changes on bone scan and $x$-ray seen within 3-6 months, and changes on computed tomography and magnetic resonance imaging seen within two months. ${ }^{69}$ In the future, new biochemical markers may detect changes earlier, and help to select patients for dose adjustment and continuation beyond two years.

Denosumab, a fully human monoclonal antibody to RANK-L, has been shown preclinically and in clinical trials to inhibit osteoclast-mediated bone destruction. ${ }^{76}$ In a Phase II trial that randomized breast cancer, prostate cancer, and multiple myeloma patients to zoledronic acid or denosumab, denosumab demonstrated superior suppression of the bone turnover marker, urinary N-telopeptide, compared with zoledronic acid (71\% versus 29\%, with a urinary N-telopeptide $<50 \mathrm{nM}) .{ }^{77}$ A recently published controlled Phase III trial included 2064 breast cancer patients from 322 centers with bone metastases who were randomized to subcutaneous denosumab $120 \mathrm{mg}$ or intravenous zoledronic acid $4 \mathrm{mg}$ every four weeks. This noninferiority trial actually established superiority of denosumab in delaying the time to first on-study skeletal-related event over zoledronic acid (HR $0.82, P=0.01$ ), as well as reducing the risk of developing multiple skeletal-related events (RR 0.77, $P=0.001$ ). While the total rate of side effects was similar between both groups, denosumab was associated with less renal toxicity $(4.9 \%$ versus $8.5 \%, P=0.001)$ and fewer acute-phase reactions $(10.4 \%$ versus $27.3 \%$ ). The rate of osteonecrosis of the jaw was not significantly different between denosumab and zoledronic acid $(2.0 \%$ versus $1.4 \%, P=0.39) .{ }^{78}$ This improved efficacy with denosumab, along with the convenience of administration and the more favorable renal effect profile, is expected to result in the addition of denosumab to the armamentarium of treatment for breast cancer with bone metastases.

\section{Managing bone pain as an established skeletal related complication}

Intractable bone pain occurs in $50 \%-90 \%$ of metastatic breast cancer patients with bone metastases, with up to $54 \%$ receiving short-term pain relief with treatment. ${ }^{79,80}$ The pathophysiology of bone pain is unique when compared with inflammatory pain or neuropathic pain, in that there is substantial spinal cord astrocytosis, enhanced neuronal activity through c-Fos expression, and sensitization of the central dorsal horn of the spinal cord mediated by dynorphin, a prohyperalgesic peptide. ${ }^{81}$ It is believed that both tumorinduced damage (bone destruction, pathological fracture, tissue infiltration, secondary muscle spasm, nerve compression) as well as tumor-produced factors (endothelin-1) have important roles in the generation of bone pain. ${ }^{43}$ Bone pain is generally poorly localized, with a deep boring and aching quality, and episodes of stabbing discomfort. It is particularly worse at night, and is not necessarily helped by lying down or sleeping. ${ }^{33,79}$ Current therapies focus on adequate pain control using anti-inflammatory corticosteroids and opioids, slowing down osteolysis with bisphosphonates, reducing tumor burden with radiotherapy, and stabilizing bones surgically, or with radiopharmaceuticals in selective cases. ${ }^{81,82}$

There are several trials that have examined the use of bisphosphonates to treat bone pain, but interpretation of the trial results for bone pain has been difficult, because of inconsistency in pain definition, its measurement and timing, and lack of standardized recording of analgesic use. ${ }^{83}$ A meta-analysis specifically examining bisphosphonate effects on bone pain was published in 2002. ${ }^{84}$ It included 30 well conducted trials that encompassed breast, prostate, lung, multiple myeloma, and cancer of unknown primary. The bisphosphonates studied were etidronate, pamidronate, and clodronate. The pain relief benefit is certainly appreciated in metastatic breast cancer patients (HR 1.83, 95\% CI 1.11-3.04). In the subgroup analysis, the response is significant for oral clodronate (HR 3.26, 95\% CI 1.80-5.09), but not for intravenous pamidronate (HR 2.35, 95\% CI 0.77-7.15), and the trend is unfavorable for etidronate (HR 0.28, 95\% CI 0.01-7.67). However, Lipton analyzed two pivotal trials (one with chemotherapy, another with hormone therapy, total $\mathrm{n}=751$ ), where pamidronate significantly reduced the pain score $(-0.07, P=0.015)$ and the analgesia score $(-0.06, P=0.001)$ at 24 months. ${ }^{55}$ Other new potent nitrogencontaining bisphosphonates also show promise in this field. There are at least three randomized studies that substantiate the significant and sustained pain relief afforded by zoledronic acid, and one study also improved quality of life. ${ }^{71}$ Furthermore, a Phase II study has demonstrated the feasibility of using zoledronic acid as a second-line agent for patients who have failed on pamidronate or clodronate. ${ }^{85}$ Ibandronate is probably the best studied in the bone pain literature, having utilized the European Organisation for Research and Treatment of Cancer QLQ-C30 quality of life questionnaire, pain scale (0-4) and analgesia consumption questionnaire (0-5) in all three studies (two oral and one intravenous). Both oral and intravenous ibandronate were shown to reduce bone pain, peaking within 8-12 weeks and persisting for at least 96 weeks. In addition, patients on intravenous ibandronate had improved quality of life. ${ }^{86,87}$ Thus far, oral clodronate, intravenous pamidronate, intravenous zoledronic acid, and 
oral/intravenous ibandronate have all demonstrated bone pain relief, with ibandronate showing the longest time of sustained pain relief (96 weeks). Intravenous zoledronic acid also showed an advantage as a second-line agent in a Phase II trial, whilst oral/intravenous ibandronate has the best evidence for improvement of quality of life.

Radiotherapy is an established treatment for bone pain from metastases, and is also used to treat pathological fractures and neurological complications. External beam radiotherapy can achieve pain relief within 4-6 weeks, and retreatment is possible if pain recurs. ${ }^{88}$ Multiple fractions (20 Gy/5 fractions) were equivalent to a single fraction ( $8 \mathrm{~Gy} / 1$ fraction) in achieving an overall response (59\% versus 58\%, 95\% CI 0.95-1.03), but the retreatment rate was 2.5-fold higher in the single fraction $\operatorname{arm}(P<0.00001) .{ }^{89}$ For patients with multifocal bone metastases, half-body irradiation has been shown to produce prompt pain relief (1-4 weeks) at the cost of acute toxicity (nausea, vomiting, or diarrhea in first 24-48 hours), although there was no correlation between field size and pain relief. ${ }^{90}$ The analgesic mechanism of radiotherapy is incompletely understood. Whilst radiotherapy certainly mediates some analgesic effect via tumor debulking, there is also evidence pointing towards osteoclast inhibition. ${ }^{91}$ Given the potential overlap of the mechanisms of radiotherapy and bisphosphonates, and availability of in vivo evidence, there is growing interest in combining the two treatments for synergistic effect. ${ }^{88,91}$ More recently, bone-seeking radiopharmaceuticals have been developed for palliation of refractory bone pain. These are thought to act as a substitution for the hydroxyapatite of bone, with more uptake in osteoblastic metastases where new reactive bone is formed. The response takes $2-3$ weeks to develop after administration and lasts for 3-6 months, with response rates of $55 \%-95 \%$ and complete relief in $5 \%-20 \%$. The main toxicity is flare reaction in $10 \%$ of patients and Grade 2 or less myelosuppression. ${ }^{92}$ Whilst the evidence is more established in metastatic prostate cancer, there have been a few small relevant studies in metastatic breast cancer. ${ }^{93}$ One study involving 100 patients (60 with metastatic prostate cancer, 40 with metastatic breast cancer) randomized to strontium or samarium shows improvement in Karnofsky status (+20) and reduction in pain by visual analog scale $(-4)$, with more favorable results for osteoblastic than mixed metastases. ${ }^{94}$

\section{Managing other established skeletal- related complications}

Other skeletal-related complications are equally important, because pathological fractures, hypercalcemia, and spinal cord compression occur in $35 \%, 19 \%$, and $8 \%$ of cases, respectively. ${ }^{95}$ A team approach with experienced surgeons, radiation oncologists, medical oncologists, and palliative care physicians is often necessary. Spinal cord compression, in particular, is a medical emergency. Symptoms include motor weakness (96\%), pain (94\%), sensory disturbance (79\%), and sphincter disturbance (61\%). ${ }^{96}$ The key to management is high-dose steroids, urgent radiology (magnetic resonance imaging), and prompt referral for surgical decompression and/or radiotherapy. In the randomized landmark trial by Patchell et al, surgery followed by radiotherapy demonstrated a significantly better post-treatment ambulatory rate $(84 \%$ versus $57 \%, P<0.001)$ compared with radiotherapy alone, with a significant prolonged continence rate (odds ratio [OR] $0.47, P=0.016$ ), functional ability (OR $0.24, P=0.0006)$, and motor strength (OR $0.28, P=0.001)$. In fact, survival time is also significantly better in the combined modality group (126 days versus 100 days, OR $0.60, P=0.033) .{ }^{97}$ That being said, patients with very radiosensitive tumors, multiple areas of spinal cord compression, or total paraplegia for longer than 48 hours, were excluded from the study. Given the selection bias of this trial and the controversy concerning the optimal radiotherapy regimen, surgery should be offered as upfront treatment for fit and functional patients with spinal cord compression, while radiotherapy is best reserved for the unfit, already incapacitated, or those with poor prognosis.

\section{Role of effective systemic endocrine and chemotherapy}

Effective systemic treatment is paramount not only for breast cancer bone metastases, but also for metastatic breast cancer in general. Chemotherapy is certainly an important part of systemic treatment, with good clinical evidence supporting anthracyclines and taxanes as key initial treatments, ie, capecitabine + docetaxel, liposomal doxorubicin, azaepothilone B (ixabepilone), and various other chemotherapies reserved for after failure on anthracyclines and/or taxanes. ${ }^{98-103}$ Evidence is mounting for the role of endocrine therapy, specifically for breast cancer with bone metastases. It has been observed that, among patients with recurrent breast cancer, those who previously had estrogen receptor-positive tumors are twice as likely to develop bone metastases than those who had estrogen receptor-negative tumors. ${ }^{104}$ Microarray studies in breast cancer patients have provided further proof that bone metastases occur far more frequently in estrogen receptor-positive tumors (luminal types $\mathrm{A}$ and $\mathrm{B}, 68 \%$ ), compared with HER2-positive tumors $(20 \%)$, basal tumors (7\%), and normal molecular subtypes (6\%). ${ }^{105}$ Of note, 
the genes upregulated for estrogen receptor-positive bone metastases are entirely different from those for HER2positive or basal subtype bone metastases. ${ }^{105}$ This suggests that the estrogen receptor is involved in distinct molecular pathways that endow estrogen receptor-positive tumors with the ability to metastasize to bone. Indeed, estrogen receptor signaling has now been shown to coactivate with various cofactors, such as steroid receptor coactivator 1 and peroxisome proliferator-activated receptor binding protein, induce a myriad of micro-RNAs at the nuclear level, and cross-talk with other tyrosine kinase receptors, including epidermal growth factor, HER2, and the IGF-1 receptor. ${ }^{106}$ While endocrine therapy is already a well established treatment for metastatic breast cancer patients in multiple randomized controlled trials and meta-analyses, ${ }^{107-113}$ understanding the relevant pathways involved may provide a further rationale for its use, particularly in the setting of bone metastases. In fact, current guidelines recommend endocrine therapy in preference to chemotherapy for women with hormone receptor-positive advanced breast cancer, except in the presence of rapidly progressive visceral disease, given the lower toxicity of endocrine therapy, similar overall survival when compared with chemotherapy, and slower progression of cancer in patients with endocrine-responsive disease. ${ }^{114,115}$ Therefore, for the majority of patients with new bone metastases who have estrogen receptor-positive HER2-negative luminal-type breast cancer, it may be reasonable to start with endocrine therapy (a third-generation aromatase inhibitor over tamoxifen for postmenopausal women, given the higher overall response and longer progression-free survival) and a bisphosphonate, particularly if the patient has had a long disease-free interval (more than two years), limited visceral recurrence, and slowly progressive disease. ${ }^{114,116}$

\section{Preventing bone metastases in early breast cancer Preclinical evidence of antitumor properties of bisphosphonates}

The antitumor properties of bisphosphonates have been examined in vitro, with bisphosphonates shown to inhibit tumor adhesion and invasion, induce tumor apoptosis, and exert an antiangiogenic effect. This evidence is especially strong for nitrogen-containing bisphosphonates. ${ }^{117}$ In vivo, bisphosphonates have been shown to reduce tumor burden and prevent new bone metastases, in a dose-dependent fashion. ${ }^{118}$ Some bisphosphonates (predominantly zoledronic acid) exhibit extraskeletal antitumor activity. Repeated injection of zoledronic acid was shown to decrease liver and lung metastases, as well as to improve survival in a murine model. The mechanism of this effect is thought to relate to its inhibition of cell migration and invasion, and induction of apoptosis in breast cancer cells. ${ }^{119}$ Bisphosphonates may also have immunomodulatory effects, given that continuing activation of $\gamma \delta$ effector $T$ cells has been demonstrated after a single dose of zoledronic acid in an ex vivo model of disease-free breast cancer patients. ${ }^{120}$ The synergism between zoledronic acid and chemotherapy may also be sequence-specific and schedule-specific. Zoledronic acid causes a 10-fold increase in tumor apoptosis in vitro when administered 24 hours after doxorubicin, mediated by inhibition of the mevalonate pathway, possibly because cells sensitized by chemotherapy facilitate uptake of bisphosphonates, leading to G2/M phase cell cycle arrest. ${ }^{121}$ This hypothesis is being tested in a neoadjuvant setting in the randomized Phase II ANZAC (zoledronic acid 24 hours after 5-fluorouracil-epirubicin-cyclophosphamide) study, and it may have important implications for dose scheduling of bisphosphonates in the future. ${ }^{117}$

\section{Clinical evidence in adjuvant breast cancer trials}

Three randomized trials commenced in the 1990s explored the use of clodronate in the adjuvant setting for early breast cancer patients. Diel et al randomized 302 patients with detectable tumor cells in bone marrow to $1600 \mathrm{mg}$ clodronate daily for two years or to no clodronate treatment, ${ }^{122}$ Saarto et al evaluated the use of clodronate for three years in 299 high-risk node-positive patients, ${ }^{123}$ and Powles et al published the largest cohort involving 1069 patients randomized to two years of clodronate or placebo. ${ }^{74}$ The study endpoints were incidence of distant metastases (bone, visceral, local, nonskeletal) and overall survival. The comparison of the three trials is illustrated in Table 4. These trials produced quite discordant results. Bone metastasis-free survival and nonskeletal-free survival were most favorable for clodronate in the Diel et al study, less favorable in the Powles et al study, and unfavorable in the Saarto et al study. Similarly, for patients on clodronate, overall survival was considerably improved for the Diel et al study (HR0.50, $P=0.049),{ }^{124}$ was improved in the Powles et al study (HR 0.74, $P=0.041),{ }^{125}$ and was worse in the Saarto et al study (HR 1.33, $P=0.13$ ). ${ }^{123}$ The discrepancy in these trials may be explained by variability in sample size, study populations, and study methodology. In the Saarto et al trial, there is imbalance of baseline characteristics between treatment arms, including estrogen receptor-negative subgroup (35\% in clodronate group and 23\% in control group) and postmenopausal women $(52 \%$ in the clodronate group 
Table 4 Comparison of the three clodronate trials. Although all three trials tested two years of clodronate $1600 \mathrm{mg} / \mathrm{day}$ against placebo, the study populations are quite different. This may result in variability in the results

\begin{tabular}{|c|c|c|c|}
\hline & Diel et al ${ }^{124}$ & Powles et al ${ }^{125}$ & Saarto et al ${ }^{123}$ \\
\hline Patients (n) & 302 & 1069 & 299 \\
\hline Age & 51 & 53 & 52 \\
\hline Menopausal status & Pre- and post- & Pre- and post- & Pre- and post- \\
\hline Nodal status & $\mathrm{N}_{0}$ and $\mathrm{N}+$ & $\mathrm{N}_{0}$ and $\mathrm{N}+$ & $\mathrm{N}+$ \\
\hline Adjuvant therapy & Yes & Yes & Yes \\
\hline Bone marrow micromets & Yes & No & No \\
\hline Clodronate dose & $1.6 \mathrm{~g} \mathrm{PO}$ & $1.6 \mathrm{~g} \mathrm{PO}$ & $1.6 \mathrm{~g} P O$ \\
\hline Duration of treatment & 2 years & 2 years & 3 years \\
\hline Follow-up time to-date & 8.5 years & 5.6 years & 10 years \\
\hline Intent-to-treat analyses & ?Yes & Yes & Yes \\
\hline Bone recurrence $(\mathrm{HR})^{\mathrm{a}}$ & $0.90(P=0.770)$ & $0.692(P=0.043)$ & $1.23(P=0.35)$ \\
\hline Visceral recurrence $(H R)^{a}$ & $0.95(P=0.222)$ & $0.84(P=0.24 I)$ & $1.61(P=0.015)$ \\
\hline Death $(H R)^{a}$ & $0.50(P=0.049)$ & $0.743(P=0.04 I)$ & $1.33(P=0.13)$ \\
\hline
\end{tabular}

Notes: a Hazard ratio (HR) less than $\mathrm{I}$ is in favor of treatment for preventing the specified outcome. HR more than $\mathrm{I}$ is against the treatment preventing the specified outcome. $P$ value of less than 0.05 (in bold) is considered statistically significant.

and $43 \%$ in the control group). Also, post-menopausal women were given endocrine therapy but not chemotherapy in this study. ${ }^{126}$ Although heterogenous, these trials, when analyzed together, produce a nonsignificant trend favoring clodronate for bone and visceral metastases (Figure 3).$^{53}$ In an updated meta-analysis in 2007, the overall survival (HR 0.75, 95\% CI 0.31-1.82), bone metastasis-free survival (HR 0.68, 95\% CI 0.38-1.23), and nonskeletal metastasis-free survival (HR $0.89,95 \%$ CI $0.40-1.98$ ) remain favorable but nonsignificant for clodronate. ${ }^{127}$ Results from the large National Surgical Adjuvant Breast and Bowel Project 34 (NSABP-B34) trial (3323 Stage I-III breast cancer patients on chemotherapy and/or endocrine therapy, randomized to adjuvant clodronate or placebo for three years) are eagerly awaited.

Adjuvant zoledronic acid has also been evaluated for early breast cancer. The first report came from the Austrian Breast Cancer Study Group (ABCSG-12). In this study, 1803 premenopausal patients with Stage I or II hormone-positive breast cancer and on monthly goserelin were randomized in a two by two factorial design to receiving either tamoxifen or anastrazole, with or without zoledronic acid $4 \mathrm{mg}$ every six months, for a duration of three years and a median follow-up of four years. ${ }^{128}$ Whilst the study was underpowered to demonstrate a disease-free survival or recurrence-free survival difference between the endocrine therapies tamoxifen and anastrazole ( $P=0.59$ and $P=0.53$, respectively), there was in fact a $36 \%$ improvement in disease-free survival (absolute difference $3.2 \%$ ) for patients on zoledronic acid $(P=0.01)$. Overall survival was not significantly different, but there was a trend favoring zoledronic acid (HR 0.60, 95\% CI $0.32-1.11, P=0.11)$. Of note, the benefit was not limited to skeletal events, but applied to all distant metastatic sites and locoregional recurrence rates. A direct antitumor effect of zoledronic acid seems an unlikely explanation for this, given the infrequent six-monthly dosing. A more plausible explanation may be the inhibitory effect of zoledronic acid on dormant tumor cells in the bone marrow. ${ }^{129}$ Furthermore, the ABCSG-12 bone mineral density (BMD) sub-study ( $n=404)$ shows that 2 years after completion of treatment, patients who received zoledronic acid had increased BMD ( $+4 \%$ at lumbar spine, $P=0.02$ ), whereas patients who had not received zoledronic acid still had decreased BMD $(-6.3 \%$ at lumbar spine, $P=0.001) .{ }^{130}$ Another intriguing trial is the parallel Zometa ${ }^{\circledR}$-Femara ${ }^{\circledR}$ bone loss prevention research (Z-FAST, ZO-FAST), where 2195 postmenopausal women receiving five years of letrozole are randomized to early zoledronic acid (beginning of the study) or delayed zoledronic acid (when $\mathrm{T}$ score is $\leq 2.0$ or an osteoporotic fracture had occurred). When commenced, zoledronic acid was given every six months for up to five years. Likewise, in both Z-FAST and ZO-FAST, BMD improved in the early treatment group and decreased in the delayed treatment group, with the absolute difference in mean lumbosacral and total hip BMD of $+6.7 \%$ and $+5.2 \%$ favoring the early treatment group at a 36 month follow up in Z-FAST $(P<0.001)$, and mean L2-L4 BMD of $+9.29 \%$ also favoring the early treatment group at 36 months in ZO-FAST $(P<0.001) .{ }^{131,132}$ Moreover, in a combined interim analysis of Z-FAST and ZO-FAST at 12 months, disease recurrence was less in the early treatment group than in the delayed treatment group ( 7 events vs 17 events, $P=0.0401$ ). ${ }^{133}$ This difference was upheld in the ZO-FAST study at 36 months 


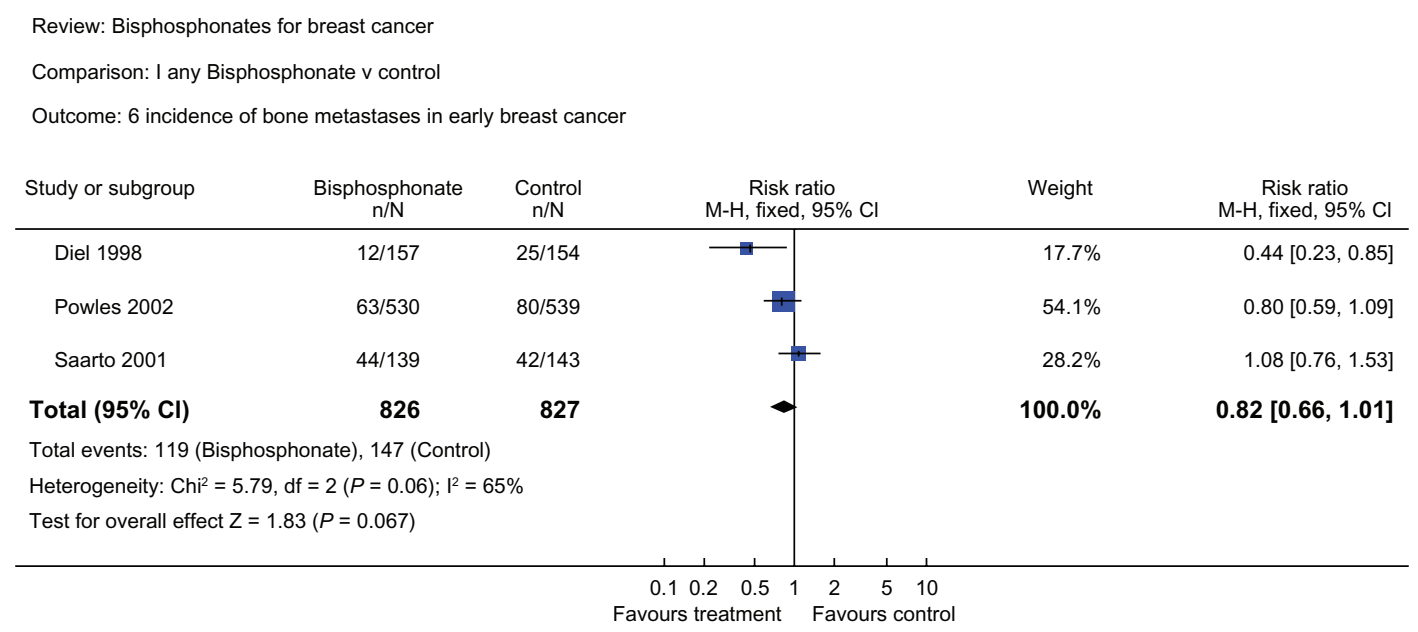

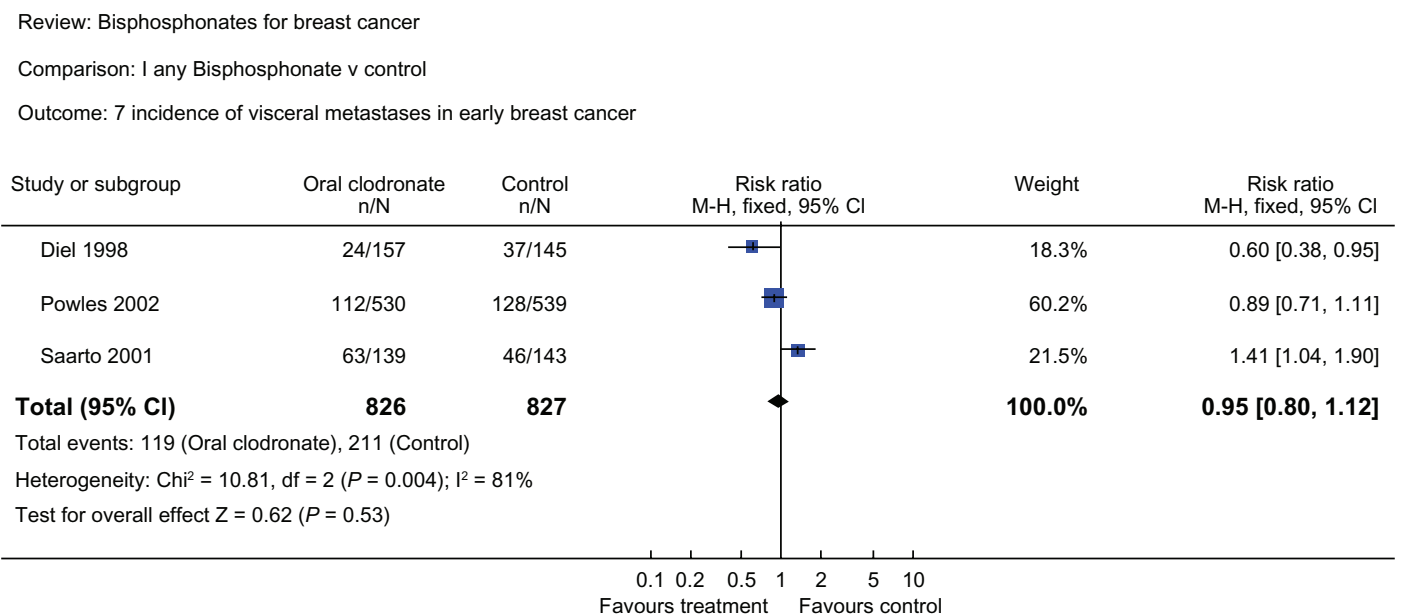

Figure 3 Meta-analysis of clodronate trials. Overall, clodronate shows a trend in decreasing bone metastases, and less so for visceral metastases. Both results are nonsignificant and there is a high level of heterogeneity $\left(I^{2}=65 \%\right.$ and $81 \%, P=0.06$ and 0.004 for bone and visceral metastases respectively). Reproduced with permission from (C) Cochrane Collaboration. ${ }^{53}$

(26 versus 43 events, $P=0.0314$ ), corresponding to a relative risk reduction of $41 \%$ and an absolute difference of $3.2 \%$ disease-free survival improvement. ${ }^{131}$ The benefit, like in the ABCSG-12 trial, was seen in both local recurrence $(0.4 \%$ versus $1.9 \%)$ and distant recurrence (3.8\% versus $5.6 \%$ ). The Z-FAST study also reports a smaller number of disease recurrence rate between early and delayed treatment group $(3.0 \%$ vs $5.3 \%)$ at 36 months follow up, but the result is not significant $(P=0.127) .{ }^{132}$

AZURE (the Adjuvant Zoledronic Acid to redUce Recurrence trial) is one of the largest zoledronic acid trials, and randomized 3360 patients from 174 centers to receive neoadjuvant chemotherapy and/or endocrine therapy \pm zoledronic acid $4 \mathrm{mg}$ intravenously every 3-4 weeks for six doses, then three-monthly $\times 8$ and 6-monthly $\times 5$ to complete five years of treatment. In an exploratory analysis of the AZURE trial, comprising neoadjuvant chemotherapy with or without an intensive zoledronic acid schedule $(\mathrm{n}=205)$, there was a significantly improved pathological complete remission rate $(10.9 \%$ versus $5.8 \%, P=0.033)$ and residual invasive tumor size ( $28.2 \mathrm{~mm}$ versus $42.4 \mathrm{~mm}, P=0.002)$ in the zoledronic acid chemotherapy combination. ${ }^{134}$

However, in the second interim analysis of the AZURE trial, with a median follow-up of 59 months, there was equivalent disease-free survival in both the zoledronic acid and control groups (377 versus 375 events, $\mathrm{HR}=0.98$, $P=0.79) .{ }^{135}$ It is difficult to understand the conflicting results between the ABCSG-12 and AZURE trials, but there are differences in the trial designs (Stage I/II in ABCSG-12 versus Stage II/III in AZURE), additional adjuvant treatments (no adjuvant chemotherapy in ABCSG-12 versus $96 \%$ patients receiving adjuvant chemotherapy in AZURE) and in patient selection (all premenopausal in ABCSG-12 versus only $35 \%$ premenopausal in AZURE) that may help explain the 
disparate results. ${ }^{128,136}$ Interestingly, in the AZURE trial, in a subgroup of women $(n=1101)$ who had more than five years of menopause, overall survival was improved by $21 \%$ (HR $0.71, P=0.017$ ). In general, subgroup analyses need to be interpreted cautiously, but this does generate the interesting hypothesis that zoledronic acid may manifest higher antitumor activity in a microenvironment with a low estrogen level. This may explain why the trial result was positive in the ABCSG-12 trial, which involved premenopausal women, all with menopause artificially induced by goserelin. ${ }^{136}$ That said, given the negative result in the AZURE trial, zoledronic acid currently cannot be recommended as a standard adjuvant therapy for breast cancer. The results from the SUCCESS trial (3754 Stage I-III breast cancer patients on sequential thirdgeneration chemotherapy followed by endocrine therapy, randomized to zoledronic acid for two years or five years) may shed some light on the role of adjuvant zolendronate in the near future. ${ }^{129}$

\section{New advances in management of breast cancer bone metastases}

From the 1990 s to the last decade, there has been a transformation in both our perception and approach to treatment of bone metastases in breast cancer. It has changed from a very high prevalence of skeletal-related events of $80 \%$ (1975-1991) to 50\% (1999-2007). ${ }^{95,137}$ It has also changed from a much feared comorbidity to a manageable complication, and it has changed from reactive palliative management with analgesia, surgery, and radiotherapy, to pre-emptive management with bisphosphonates to prevent skeletalrelated complications. In the last 10 years, there has been an explosion of knowledge about the pathophysiology of bone metastases in breast cancer, particularly through a plethora of preclinical studies and translational research. The next 10 years is going to witness an evolution in the management of bone metastases, heading towards therapies focusing specifically on the very mechanism of bone metastases, as well as utilization of biomarkers to guide therapy.

\section{Novel "bone cycle" inhibitors}

Gene expression profiling and subculturing of cell lines that metastasize to bone have paved the way for understanding the pathophysiology of bone metastases. ${ }^{138}$ Having discovered the "vicious cycle" of bone metastases, scientists have started to design novel agents specifically targeting these pathways. Many of these compounds are already being tested in clinical trials (Table 5). The first of this class of drugs to succeed in Phase III randomized controlled trials is denosumab, a fully human monoclonal antibody against the key factor, RANK-L, in an osteoclast-mediated vicious cycle. ${ }^{139}$ Recently, denosumab has shown superiority over zoledronic acid in delaying skeletal-related events in both metastatic breast cancer (HR 0.82, $P=0.01$ ) and prostate cancer (HR 0.82, $P=0.0002$ ). ${ }^{78,140}$ Denosumab is administered subcutaneously $120 \mathrm{mg}$ once a month. As discussed previously, it has fewer acute-phase reactions, such as fever, myalgia, or arthralgia, and does not need renal monitoring, although hypocalcemia occurs more frequently than for zoledronic acid. ${ }^{78}$

Another important class is the TGF- $\beta$ inhibitors. Approximately $55 \%$ of breast cancers may exhibit TGF- $\beta$ activity via a 153 -gene TGF- $\beta$ response signature. ${ }^{141}$ Whilst a global reduction in the TGF- $\beta$ receptor can exert a potent suppressive effect on tumor proliferation, there is an overproduction of this multifunctional cytokine in the setting of breast cancer bone metastases. This then induces osteolysis and angiogenesis via Smad 3, and drives epithelial-mesenchymal transition and tumor invasion via multiple signaling pathways (eg, HER2 and ras). ${ }^{142,143}$ In preclinical studies, TGF- $\beta$ antagonism is shown to suppress tumor growth and reduce lung/bone metastases by $40 \%$ in vivo. The effect appears to be most potent in basal-like (triple-negative) breast cancer cell lines. ${ }^{143}$ Currently, many TGF- $\beta$ antagonists have been entered into early phases of clinical development, including antisense oligodeoxynucleotide AP 12009 (Phase I/II for melanoma, pancreatic cancer, and colorectal cancer completed, and Phase III for anaplastic astrocytoma ongoing), monoclonal antibody GC1008 that targets all three isoforms of TGF- $\beta$ (Phase I for melanoma and renal cell carcinoma completed, and Phase II for mesothelioma ongoing) and the TGF- $\beta$ type I receptor kinase inhibitor, LY2157299 (Phase I in combination with temozolomide and radiotherapy for glioma to commence, and Phase II in hepatocellular carcinoma to commence). ${ }^{63,143}$

Src is a prototype of the nonreceptor tyrosine kinases that promote cellular proliferation, differentiation, motility and survival, having mediated signaling via the endothelial growth factor receptor, IGF-1 receptor, platelet-derived growth factor receptor, and hepatocyte growth factor/scatter factor receptor. ${ }^{144}$ In breast cancer, high levels of Src are implicated in increased osteoclast activity by forming ruffled borders, growth and survival via endothelial growth factor receptor, HER2, and PI3-kinase/Akt pathways, and hormone resistance. ${ }^{145}$ Dasatinib is a multitargeted Src inhibitor used in chronic myelogenous leukemia, which also inhibits Bcr-abl, c-kit, platelet-derived growth factor 
Table 5 Novel agents in development with specific targets on the "vicious cycle" of bone metastases. Some of these agents have entered the Phase III trial setting 8 ,42,138, 140,143,144,148-150

\begin{tabular}{|c|c|c|c|}
\hline Drug & Target & Mechanism of action (of target) & Stage of development \\
\hline \multicolumn{4}{|c|}{ Inhibitor of osteoclast differentiation } \\
\hline \multirow[t]{2}{*}{ Denosumab (AMG I62) } & Humanized $A B$ to RANK-L & Osteoclast activation and survival & Phase III positive (breast CA) \\
\hline & & & Phase III positive (prostate CA) \\
\hline \multicolumn{4}{|c|}{ Inhibitor of osteolytic "vicious cycle" } \\
\hline CAL & Antibody to PTHrP & Tumor activation of osteoclast & Phase I \\
\hline \multirow[t]{2}{*}{ GC-1008 } & Inhibitor of TGF- $\beta$ RI, 2,3 & Osteoclast activation of tumor & Phase II (mesothelioma) ongoing \\
\hline & & & Observational (renal, melanoma) \\
\hline \multirow[t]{3}{*}{ AP-I 2009 (trabedersen) } & Antisense oligodeoxynucleotide & Osteoclast activation of tumor & Phase I/II (pancreatic, melanoma, \\
\hline & specifically directed against & & CRC) completed \\
\hline & TGF- $\beta 2$ mRNA & & $\begin{array}{l}\text { Phase III anaplastic astrocytoma } \\
\text { ongoing }\end{array}$ \\
\hline \multicolumn{4}{|c|}{ Inhibitor of osteoclast signal transduction } \\
\hline SB203580 & Inhibitor of P38 MAPK & $\begin{array}{l}\text { Produces IL-I and TNF which } \\
\text { activates osteoclast }\end{array}$ & In vivo data completed \\
\hline Bortezomib & Proteasome inhibitor & $\begin{array}{l}\text { Promotes osteoclast differentiation } \\
\text { through nuclear NF- } \mathrm{KB}\end{array}$ & In use in multiple myeloma \\
\hline \multicolumn{4}{|c|}{ Inhibitor of enzymatic activity } \\
\hline Saracatinib (AZD-0530) & Dual Src/abl kinase inhibitor & $\begin{array}{l}\text { Form ruffled border of osteoclast; } \\
\text { crosstalk with multiple pathways } \\
\text { (HER2, ER) }\end{array}$ & $\begin{array}{l}\text { Phase II (breast and prostate CA) } \\
\text { ongoing }\end{array}$ \\
\hline Dasatinib & $\begin{array}{l}\text { Non-specific inhibitor of Src } \\
\text { (also inhibits Bcr-abl, c-kit, } \\
\text { PDGFR-beta, ephA2) }\end{array}$ & $\begin{array}{l}\text { Form ruffled border of osteoclast; } \\
\text { cross-talk with multiple pathways } \\
\text { (HER2, ER) }\end{array}$ & $\begin{array}{l}\text { Phase II (breast CA): } 2 \text { completed, } \\
3 \text { ongoing, in use in CML }\end{array}$ \\
\hline Odanacatib (MK-0822) & Inhibitor of cathepsin K & Breakdown of collagen in bone & Phase II (breast CA), completed \\
\hline \multicolumn{4}{|c|}{ Inhibitor of cell-matrix interaction } \\
\hline SC5663I & $\begin{array}{l}\text { Vitronectin receptor, an } \\
\alpha_{\mathrm{v}} \beta_{3} \text { integrin }\end{array}$ & $\begin{array}{l}\text { Allows osteoclasts adhere } \\
\text { to bone surface }\end{array}$ & Phase I \\
\hline \multicolumn{4}{|l|}{ Chemokine inhibitor } \\
\hline CTCE-9908 & Inhibitor of CXCR4 & Prevents tumor migration to bone & Phase I/II completed \\
\hline \multicolumn{4}{|l|}{ Endothelin inhibitor } \\
\hline Atrasentan (ABT-627) & Inhibitor of endothelin A receptor & Stimulates osteoblast proliferation & Phase III (prostate CA) \\
\hline \multicolumn{4}{|c|}{ Chemotherapy: microtubule stabilizer } \\
\hline Sagopilone & $\begin{array}{l}\text { Microtubule stabilizer/ } \\
\text { epothilones (like taxane) }\end{array}$ & $\begin{array}{l}\text { Inhibits tumor growth } \\
\text { and bone resorption }\end{array}$ & $\begin{array}{l}\text { In vivo, ex vivo completed } \\
\text { Phase II (breast CA) completed }\end{array}$ \\
\hline
\end{tabular}

Abbreviations: $A B$, antibody; CA, carcinoma; CML, chronic myelogenous leukemia; ER, estrogen receptor; IL-I, interleukin-I; TNF, tumor necrosis factor; CXCR4, C-X-C chemokine receptor type 4; PDGFR, platelet-derived growth factor receptor; CML, chronic myelogenous leukemia; MAPK, mitogen-activated protein kinase; PTHrP, parathyroid hormone-related protein; TGF- $\beta$, transforming growth factor beta.

R-beta, and ephA2. ${ }^{144}$ In vitro, it is shown to cause maximal inhibition on triple-negative breast cancer cell lines, particularly in combination with cytotoxic chemotherapy. ${ }^{145}$ In vivo, dasatinib inhibits osteoclast differentiation and activity, and rapidly lowers calcium levels. ${ }^{145}$ Two trials researching dasatinib in the setting of triple-negative and triple-positive breast cancer have now been completed. Several ongoing Phase II trials include one comparing once-daily versus twice-daily dosing, another combining dasatinib and weekly paclitaxel, and a third comparing dasatinib versus zoledronic acid. ${ }^{63} \mathrm{~A}$ dual specific Src/abl inhibitor, saracatinib, has also commenced a Phase II trial in breast and prostate cancer with bone metastases, after demonstrating decreased levels of bone resorption markers in serum and urine in a Phase I study, suggesting a potential effect on osteoclasts. ${ }^{63,144}$

Cathepsin $\mathrm{K}$ is a cysteine protease predominantly responsible for osteoclast-mediated degradation of collagen I in the extracellular matrix, indirectly stimulated by RANK-L and TGF- $\beta$ via NFATc $1 .{ }^{138}$ High expression of cathepsin K is found on immunohistochemistry in primary breast tumor and bone metastases, but not in liver metastases. This is, in turn, associated with higher stage and negative estrogen receptor status, two poor prognostic factors in breast cancer. ${ }^{146}$ In a Phase II trial of breast cancer patients with bone metastases, odanacatib, a highly selective cathepsin K 
inhibitor, was shown to suppress urinary N-telopeptide and urinary deoxypyridinoline markers of bone resorption after four weeks of treatment to similar levels when compared with zoledronic acid. ${ }^{147}$ There are as yet no reports on its effect on skeletal-related events or quality of life.

CXCR4 is the most abundantly expressed chemokine receptor on a breast cancer cell. This "attracts" the cancer cell to the bone, where there is a high level of stromal cellderived factor-1, the only ligand of CXCR $4 .{ }^{20}$ As mentioned previously, CXCR4 is important in tumor migration, but it also has a positive role in tumor detachment from the primary site, tumor extravasation into secondary sites, and possibly in angiogenesis. ${ }^{148} \mathrm{CXCR} 4$ antagonists, be it small molecules, peptides, antibodies, or small interfering RNAs, consistently reduce bone metastases in all animal models of different cancers. ${ }^{148}$ CTCE-9908, a peptide analog of stromal cell-derived factor- 1 that acts as a competitive antagonist of CXCR4, has been studied in a Phase I/II clinical trial. It showed some preliminary signs of activity, with five patients having stable disease among the 30 patients who received the drug (including eight patients with breast cancer). ${ }^{25}$ Other options for the development of this drug include combination with chemotherapy or combination with zoledronic acid. ${ }^{138}$

Many other novel "bone cycle" inhibitors have only entered the early phase of clinical development. It is anticipated that there will be a surge of clinical trial data in the next few years. The significant results in the denosumab trials bear witness to the potential efficacy with these specific targeted therapies, and they are likely to become a crucial part of the armamentarium in the battle against bone metastases in the future.

\section{Predictive biomarkers and bone markers}

Biomarkers are a fundamental feature of the strategy of "personalizing medicine". A biomarker assay with high sensitivity and specificity may potentially help clinicians to screen high-risk patients for bone metastases, to select the right therapy for these patients, and to monitor treatment. To this end, various groups have performed specific (eg, immunohistochemistry, enzyme-linked immunosorbent assay) or global (eg, proteomic studies, gene microarray) analyses on a large collection of breast cancer tissues and correlated these with clinical outcome in order to discover gene or protein sets that will best predict bone recurrence or skeletal-related events. ${ }^{14,105,151,152}$ Bohn et al assessed the difference between 64 primary breast cancer and 16 breast cancer bone metastases using tissue microarray and immunohistochemistry, but they were only able to identify HER-2 (18.5\% versus 9\%,
$P=0.016)$ and tumor size $>2 \mathrm{~cm}(68.75 \%$ versus $40.6 \%$, $P=0.042)$ as predictive markers for bone metastases. There was no significant difference in the protein expression of the trefoil peptide, TFF-1, CXRC4, matrix metalloproteinase-1, parathyroid hormone-related protein, CD44, FGFR3, interleukin-11, and estrogen receptors/progesterone receptors between bone metastases and primary breast cancer. ${ }^{151}$ Using gene microarray and bioinformatics analysis, Smid et al found that tumors with a luminal subtype gene signature were more likely to develop bone metastases $(P=0.0031) .{ }^{105}$ Moreover, their group has developed a 31-gene signature that can predict bone metastases with a sensitivity of $100 \%$ and a specificity of $50 \%$. This compares favorably with estrogen receptor status (sensitivity $74 \%$ and specificity $63 \%$ ), which is the clinical marker most closely related to bone metastases at this stage. ${ }^{153}$ Within this gene signature, the key gene sets include trefoil protein-encoding genes (TFF1 and TFF3), genes related to the fibroblast growth factor receptor-MAPK signaling pathway, and cell adhesion. ${ }^{153}$ Other groups have utilized surface-enhanced laser desorption/ionizationassisted or matrix-assisted laser desorption/ionization time of flight for mass protein profiling of serum and plasma, particularly because serum assays are convenient for patients and therefore appealing as a simple diagnostic test. Although multiple protein peaks have been observed in the serum of breast cancer patients (not specifically with bone metastases), the results are hampered by only a small percentage of reported peaks having been structurally identified, and the results being not entirely reproducible with validation studies. ${ }^{154}$ Thus, the definitive value of proteins identified through proteomic technology is questionable at this stage, and the 2007 American Society of Clinical Oncology guidelines state that "... there is insufficient evidence to recommend use of proteomic patterns for management of patients with breast cancer". 155

Aside from protein and gene markers, the many clinical trials that have amassed over time have allowed multivariate analysis to detect clinical parameters that may predict skeletal-related events whilst patients are on treatment for bone metastases. For example, using the datasets from a large randomized Phase III trial comparing zoledronic acid and pamidronate, Brown et al have identified multiple baseline clinical parameters that significantly multiply the risk of skeletal-related events whilst on zoledronic acid treatment, including age $\geq 60$ years (HR 1.7), Brief Pain Inventory score $>3$ units (HR 2), history of skeletal-related events before study entry (HR 1.6), and predominance of osteolytic versus osteoblastic lesions (HR 1.8). ${ }^{156}$ 
To summarize, advances in science and translational research have produced a surge in potential biomarkers. Whilst many of these candidate markers still require validation in large clinical studies, it is anticipated that, in the future, there will be more sensitive and specific biomarkers than estrogen receptor positivity alone.

Bone turnover markers appear to correlate closely with skeletal-related events, and have therefore been measured frequently as secondary endpoints in bisphosphonate trials. ${ }^{157}$ Both bone formation markers (eg, bone-specific alkaline phosphatase, osteocalcin, C-terminal and N-terminal propeptides) and bone resorption markers (eg, urinary calcium excretion, urinary hydroxyproline, collagen pyridine crosslinks, and protein-bound crosslinks [N-telopeptide, C-telopeptide/type I collagen carboxyterminal telopeptide]) have been used to assess response in these trials. ${ }^{157}$ Among these biomarkers, urinary N-telopeptide excretion is regarded as the single most reliable predictive marker. In one study, N-telopeptide was significantly correlated with skeletal-related events/death $(\mathrm{r}=0.62, P<0.001$ for $0-3$ months and $r=0.46, P<0.001$ for $4-6$ months, respectively), and patients with bone metastases who had high baseline and on-treatment collagen telopeptide and urinary $\mathrm{N}$-telopeptide were 19 times and 10 times more likely to develop further skeletal-related events, respectively. ${ }^{158}$ By pooling three double-blind, randomized, controlled trials for analysis (1824 bisphosphonate-treated patients, 490 breast cancer patients treated with zoledronic acid, and 254 breast cancer patients treated with pamidronate), Coleman et al reported a 2.54-fold increase in the risk of developing a first skeletal-related event $(P<0.001)$ and a 4.84-fold increase in the risk of death $(P<0.001)$ for breast cancer patients with high N-telopeptide $(\geq 100 \mathrm{nmol} / \mathrm{mmol}$ creatinine) compared with low N-telopeptide $(<50 \mathrm{nmol} / \mathrm{mmol}$ creatinine) when treated with zoledronic acid. ${ }^{159}$ They also calculated a three-fold increase in the risk of developing a first skeletal-related event $(P<0.001)$ and a 2.23 -fold increase in the risk of death for breast cancer patients with high values of bone-specific alkaline phosphatase, when the cutoff is set at $146 \mathrm{U} / \mathrm{L} .{ }^{159}$ The value of N-telopeptide in predicting skeletal-related events for metastatic breast cancer patients on zoledronic acid is being evaluated in the prospective trial, BISMARK (Cost effective use of BISphosphonates in metastatic bone disease a comparison of bone MARKer directed zoledronic acid therapy to a standard schedule), where 1400 patients with breast cancer bone metastases on zoledronic acid $4 \mathrm{mg}$ monthly will have their urinary N-telopeptide/creatinine ratio calculated at baseline and measured every 15-16 weeks thereafter. The primary study endpoint is skeletal-related events, with secondary endpoints including quality of life, pain, analgesic use, health economics, change in systemic treatment, and survival. ${ }^{160}$ In addition to urinary N-telopeptide, urinary C-telopeptide is also showing some promise as a bone biomarker, because a small prospective nonrandomized study demonstrated significantly lower C-telopeptide levels at 12 and 18 months for patients who did not develop skeletal-related events ( $P=0.005$ and $P=0.001$, respectively) and significantly higher C-telopeptide levels at baseline and 18 months for patients who had disease progression $(P=0.040$ and $P=0.006$, respectively). ${ }^{161}$ The placebo-controlled trials of oral ibandronate also showed a decrease of C-telopeptide from baseline in the two ibandronate arms $(-39 \%$ for ibandronate $20 \mathrm{mg},-55 \%$ for ibandronate $50 \mathrm{mg}$, and $+47 \%$ for placebo, $P<0.001) .{ }^{57}$ The 2011 American Society of Clinical Oncology guidelines recommend against using biochemical biomarkers to monitor treatment, because there are currently "... no published studies in which participants have been assigned to treatment based on N-telopeptide status". ${ }^{70}$ However, if these bone turnover markers can be validated by Phase III biomarker trials, such as BISMARK, this may change our practice in the future.

\section{Shifting from the "reactive" to "proactive" management paradigm}

At present, the paradigm for managing bone metastases is focused on symptom management and prevention of complications after bone metastases are diagnosed. Both the National Comprehensive Cancer Network and American Society of Clinical Oncology do not endorse routine blood tests, tumor markers, or imaging studies for surveillance. ${ }^{162,163}$ This is based on a Cochrane meta-analysis showing no significant overall survival and disease-free survival advantage offered by intensive surveillance as opposed to routine clinical visits in early breast cancer, in all subgroups stratified by tumor size and lymph node status. ${ }^{164}$ Therefore, a high-risk early breast cancer patient will most likely only have an annual mammogram as surveillance. The conundrum is that even though the existing guidelines recommend commencing bisphosphonates as soon as there is radiological evidence of bone metastases, a patient with undetected bone metastases is unlikely to have imaging until she presents with her first skeletal-related event (bone pain, fracture, spinal cord compression, or hypercalcemia). This reactive approach relies on the fact that the evidence base for bone agents (including bisphosphonates) in breast cancer was established on the 
basis of studies in patients with clinically established bone metastases, with evidence for prevention limited and awaited from key adjuvant studies. ${ }^{53}$ Furthermore, the strategy of surveillance for metastases is based on the premise that overall survival is not altered. ${ }^{162,163}$ However, with better molecular characterizing of patient risk groups and the use of a more personalized strategy of treatment by biomarker selection, this reactive approach may be challenged if data show that early intervention can alter the natural history.

Novel treatments and technologies are opening the door to new opportunities and strategies in breast cancer bone metastases. Whilst many advances (eg, adjuvant bisphosphonates, novel bone markers, biomarkers) remain to be validated in randomized, controlled trials before they can be recommended for routine clinical use, these advances taken together may one day allow clinicians to pre-emptively manage bone metastases, thereby reducing the incidence of skeletal-related events and even bone metastases in the first place. Figures $4 \mathrm{~A}$ and $4 \mathrm{~B}$ show a comparison of the current model and a hypothesized future model of the possible management in breast cancer bone metastases. The goals of the future model may be:

- Early management, ie, expectant management for highrisk patients
- Accurate assessment, ie, early detection of bone metastases before skeletal-related events occur

- Acute management, ie, tailored treatment regimes to manage individuals with skeletal-related events

- Continuing management, ie, prevention of further skeletal-related events and improved quality of life for patients with bone metastases.

\section{Identifying high-risk individuals}

There is increasing evidence that patients with elevated baseline bone resorption markers are at high risk of developing bone metastases. At the same time, genomic and proteomic profiling have been shown to correlate with disease progression and tumor aggressiveness. ${ }^{165}$ In the future, these technologies may become available in the routine clinical setting, and may be weighed into the risk stratification equation, just like grade, size, nodal status, hormone status, and HER2 status, to determine adjuvant treatment strategies.

\section{Incorporating bisphosphonates into adjuvant therapies}

Bisphosphonates are well studied for preventing and delaying skeletal related complications, improving bone pain and quality of life in advanced breast cancer, as well as correcting

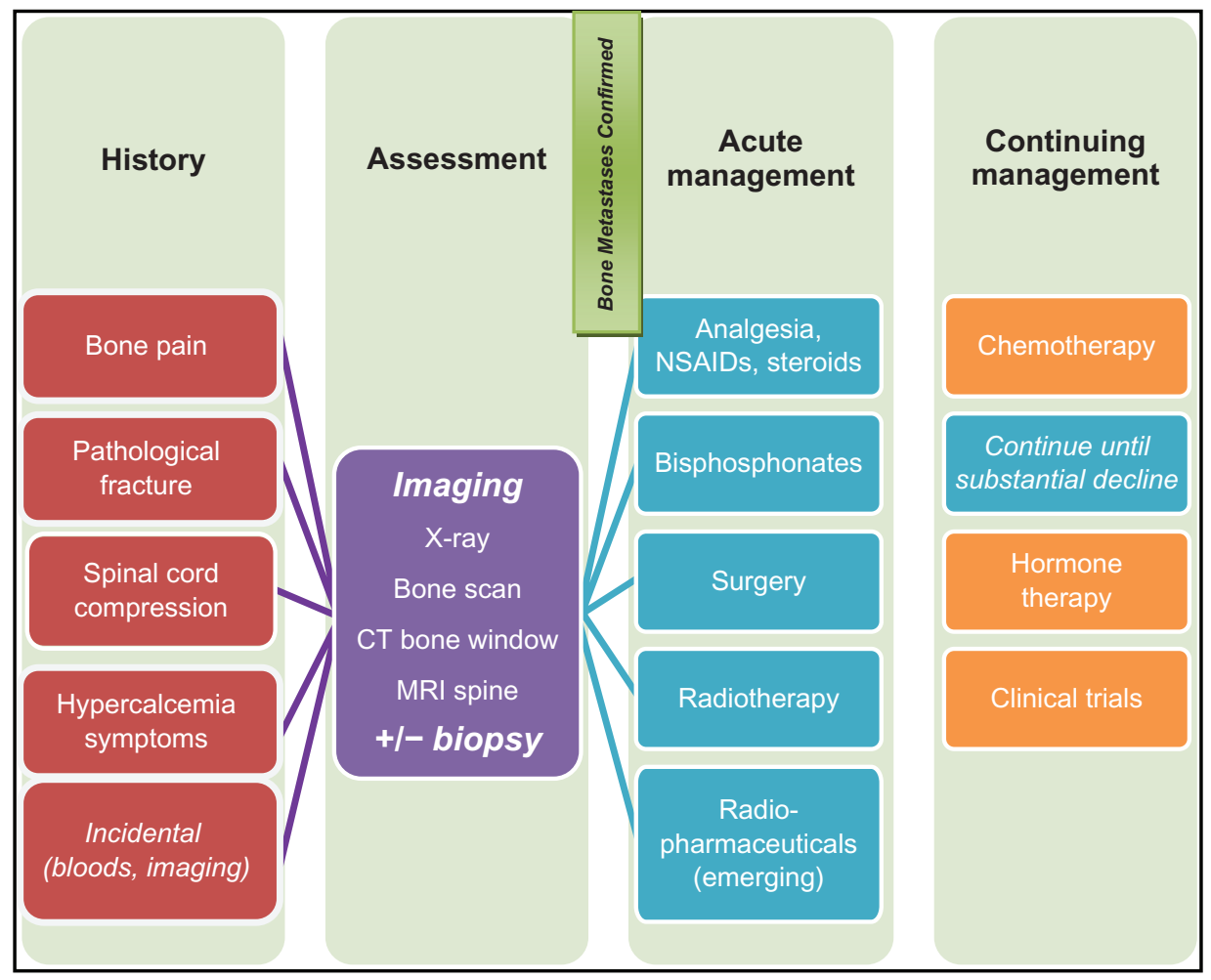

Figure 4A Current paradigm with a rather "reactive focus" on bone metastases. 


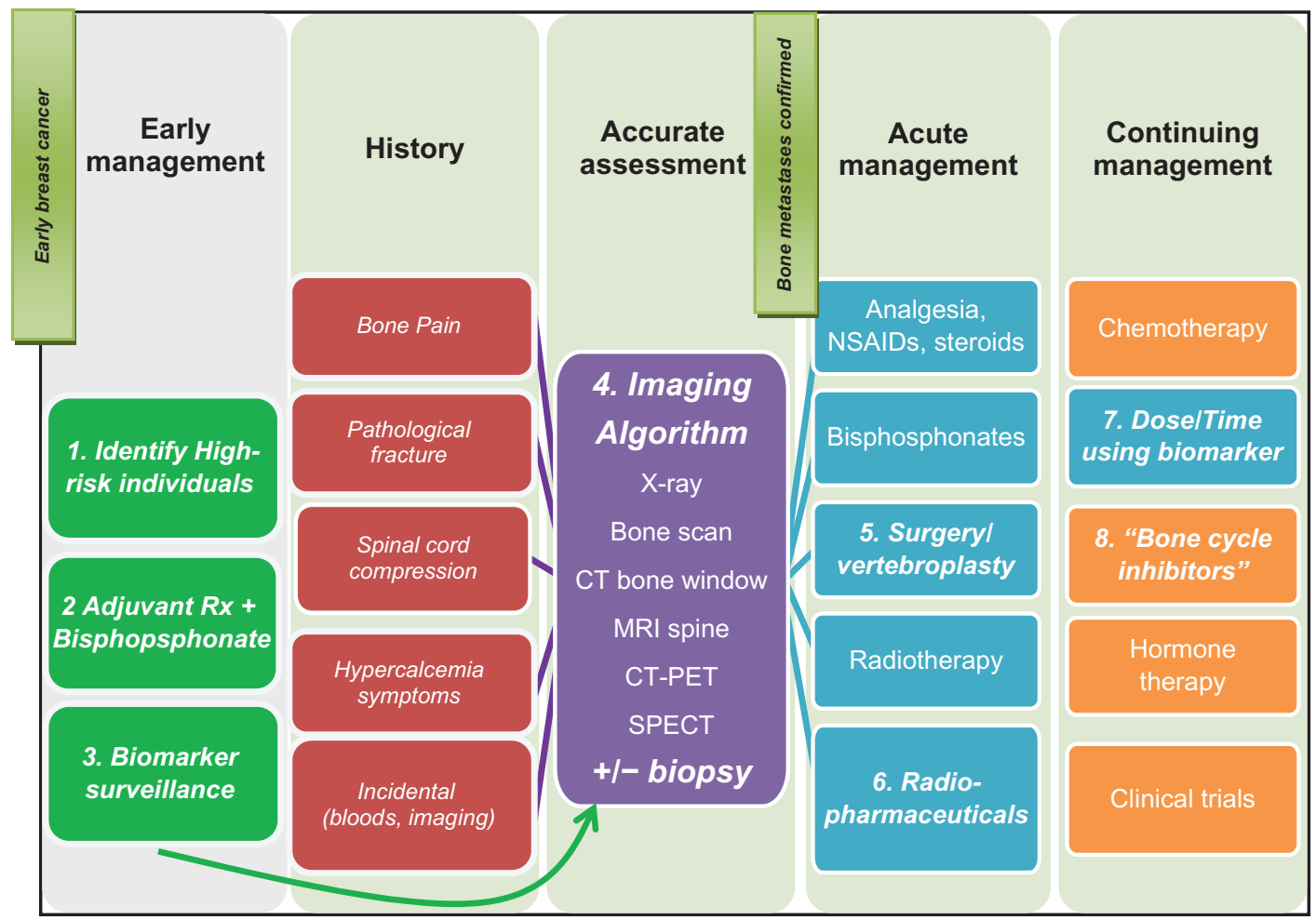

Figure 4B Future model of cancer care- shifting from "reactive" to "proactive focus" on bone metastases.

Table 6 Summary of benefit and evidence (phase III or meta-analysis) for bisphosphonate in advanced and early breast cancer

Metastatic breast cancer (bone)

Prevents skeletal related events

Delays onset of skeletal complications Improves bone pain

Improves quality of life

Corrects hypercalcemia

Does not improve overall survival
Meta-analysis (ALL): risk of SRE $\downarrow 15 \% *$

IV ZOL >PAM: additional $\downarrow 20 \%$ SRE ( $\downarrow 30 \%$ SRE in lytic subgroup) at 25 months*

Meta-analysis (ALL): delays SRE by 3-6 months

Meta-analysis (CLO, PAM): increases $2.4 x$ of patients with pain relief within 12 weeks*

IV PAM: $52 \%$ vs $40 \%$ placebo in pain at 48 weeks; sustained pain relief 48 weeks*

IV ZOL = PAM: BPI score no difference. ZOL vs PAM $\downarrow$ surgery and RT at 100 weeks

PO IBA: visual pain score -0.10 vs +0.20 for placebo; sustained relief 96 weeks* IV IBA: visual pain score -0.28 vs +0.21 for placebo; sustained relief 96 weeks*

PO IBA: 3x improvement in EORTC QLQ-C30 score (-8.3 placebo vs -26.8 PO IBA)* IV IBA: 4x improvement in EORTC QLQ-C30 score (-10.3 placebo vs -45.4 IV IBA)*

ZOL achieves normal calcemia in $88 \%$, PAM in $77 \%$

Meta-analysis (ALL): OS is not improved (HR 0.99, NS)
53,61

53

84,71

87,86

72

53

53

130,169

May improve overall survival

ABCSG-I 2 (ZOL): ${ }^{a} \operatorname{tam} / Z+5.2 \%$, Ana/Z $+3.1 \%$, tam only $-4.5 \%$, Ana only $-7.8 \%$ at 60 m* Z-fast, Zo-fast (ZOL): ${ }^{\text {b }}$ Lumbrosacral BMD $+5 \%$ total hip BMD $+3.5 \%$ early vs delayed treatment at 12 months*

May reduce bone metastases Meta-analysis $3 \mathrm{CLO}$ trials: trend favours CLO (HR 0.68, Cl 0.38-I.23) ABCSG-I2: $\uparrow 36 \%$ DFS at 4 years, *bone mets 23 versus 16 events (ZOL) Meta-analysis 3 CLO trials: trend favours CLO (HR 0.89, Cl 0.40-I.98) ABCSG-12: $\uparrow 36 \%$ DFS at 4 years, ${ }^{*}$ non-bone non-breast mets 8 versus 7 events (ZOL) Meta-analysis of $3 \mathrm{CLO}$ trials: ${ }^{c}$ OS improved by $18 \%$ (HR 0.82 NS) Meta-analysis of $3 \mathrm{CLO}$ trials: ${ }^{\text {t }}$ trend favours CLO (HR 0.75, NS) ABCSG: - I2: trend favouring ZOL (HR 0.60, NS)

Notes: *Significant result: at least $<0.05$. aACSG I2: Zoledronic acid given at $4 \mathrm{mg}$ every 6 monthly for 3 years; ' Z-fast, Zo-fast: Zoledronic acid given at 4 mg every 6 months, starting at beginning of study in early treatment group and only when $T<-2.0$ or pathological fracture in delayed treatment group. Zoledronic acid is given until 5 years of the study period; 'Meta-analysis from Cochrane Review 2002; dMeta-analysis from British Journal of Cancer 2006.

Abbreviations: ALL, all bisphophonates; ZOL, zoledronic acid; IBA, ibandronate; PAM, pamidronate; CLO, clodronate. 
hypercalcemia (Table 6). Recently, there is a suggestion from current clinical evidence that there may be a subgroup of patients who may benefit from adjuvant zoledronic acid therapy, perhaps postmenopausal women with low estrogen levels. ${ }^{136}$ Patients identified as high-risk in the right subgroup may be offered bisphosphonates as part of adjuvant treatment, if future studies validate the efficacy of bisphosphonates in preventing metastases and possibly improving survival. More importantly, the optimal sequence/schedule for obtaining an antitumor effect with chemotherapy and bisphosphonate therapy needs to be defined. ${ }^{117}$

\section{Biomarkers in surveillance}

CA15-3 is not recommended as part of surveillance. Although it has good specificity (95\%) versus benign breast disease, its sensitivity is only $30 \%$ for recurrence and $60 \%-90 \%$ for metastatic disease. ${ }^{166}$ Bone-specific biomarkers are looking promising as predictors of bone metastases. ${ }^{160}$ If a biomarker assay with high sensitivity is developed, it may potentially help clinicians make decisions about early imaging and intervention before skeletal-related events arise.

\section{An imaging algorithm}

To increase the detection rate of bone metastasis and formulate the baseline assessment from which interval imaging can be accurately compared, bone scan has a sensitivity of $62 \%-100 \%$ and a specificity of $78 \%-100 \%$. Computed tomography is better than bone scanning in detecting lesions in the spine and calvarium, but only limited anatomical areas can be scanned at a time. On the other hand, positron emission tomography and single photon emission computed tomography have high specificity $(96 \%-100 \%$ and $91 \%-93 \%$, respectively). ${ }^{6}$ In the future, a combined approach using these high technology imaging modalities may improve the early detection rate.

\section{Vertebroplasty}

Vertebroplasty is a good alternative to surgery for some vertebral compression fractures in patients unfit for surgery, because this percutaneous technique is minimally invasive and generally well tolerated. There is clinical evidence for significant improvement in pain and physical function in patients with bone metastases undergoing vertebroplasty. ${ }^{167}$

\section{Radiopharmaceuticals}

Radiopharmaceuticals have a particularly key role in multifocal bone metastases. There is clinical evidence of synergism between radiopharmaceuticals and chemotherapy, which is generating some interest. ${ }^{93}$ Having availability of vertebroplasty and radiopharmaceuticals may help improve quality of life for selected patients.

\section{Biomarkers to monitor disease progression and assess response}

The value of $\mathrm{N}$-telopeptide in predicting skeletal-related events for breast cancer bone metastases patients on zoledronic acid is being studied in BISMARK. ${ }^{160}$ If biomarker levels can be linked clearly to clinical outcome and treatment efficacy, it may become an important tool for monitoring and guiding duration of therapy with bisphosphonates or other bone cycle-targeted therapies. ${ }^{168}$

\section{Novel "bone cycle" inhibitors}

The development of these drugs is mostly in the early clinical stages, but some compounds are already being tested in Phase II/III settings. In addition, denosumab has been shown to be superior to zoledronic acid in preventing skeletal-related events. ${ }^{78}$ These targeted treatments are likely to become key in the battle against bone metastases in the years to come.

\section{Conclusion}

In conclusion, there has been major progress in the management of bone metastases from breast cancer in the last 20 years. Bisphosphonates are an important part of standard management of bone metastases, by reducing skeletal-related events, and improving bone pain and quality of life in some patients. More recently, new bone-targeting agents, such as denosumab, have emerged which appear to have even greater efficacy than zoledronic acid for preventing skeletal complications. In the adjuvant setting in early breast cancer, bisphosphonates may have a role in preventing both bone and non-bone metastases. However, there are conflicting results from the currently reported adjuvant clodronate and zolendronate studies. Firm conclusions on adjuvant bisphosphonates await final results from all completed studies. With better understanding of the biology and mechanism behind bone metastases, novel agents specifically targeting the osteolytic/osteoblastic vicious cycle are being developed with great promise. Together with advances in predictive biomarkers, bone turnover markers, multimodality imaging, interventional radiology, radiotherapy and surgery, these new technologies will change the way we manage breast cancer patients in the future.

\section{Disclosure}

The authors report no conflicts of interest in this work. 


\section{References}

1. Galasko C. The anatomy and pathways of skeletal metastases. In: Weiss L, Gilbert A, editors. GK Hall: Boston. Bone Metastases. 1981:49-63.

2. Rubens RD, Coleman R. Bone metastases. In: Abeloff M, Armitage J, Lichter A, Niedberhuber J, editors. Churchill Livingstone: New York. Clinical Oncology. 1995:643-65.

3. Body J. Bisphosphonate in breast cancer and other solid tumours. In: Rubens R, Mundy G, editors. Martin Dunitz Ltd: London. Cancer and the Skeleton. 2000:231-243.

4. Colleoni M, O’Neill A, Goldhirsch A, Gelber RD, Bonetti M, et al. Identifying breast cancer patients at high risk for bone metastases. [see comment]. Journal of Clinical Oncology. 2000;18(23):3925-3935.

5. Coleman RE, Rubens RD. The clinical course of bone metastases from breast cancer. British Journal of Cancer. 1987;55(1):61-66.

6. Domchek S, Younger J, Finkelstein D, Seiden M. Predictors of skeletal complications in patients with metastatic breast carcinoma. Cancer. 2000;89(2):363-368.

7. Rosenberg AE. Chapter 26: Bones, Joints, and Soft-Tissue Tumors. In: Kumar V, Abbas A, Fausto N, Aster J, editors. Saunders: Philidelphia. Robbins and Cotran Pathologic Basis of Disease. 2009.

8. Roodman GD. Mechanisms of bone metastasis.[see comment]. New England Journal of Medicine. 2004;350(16):1655-1664.

9. Guise T. Examining the metastatic niche: targeting the microenvironment. Seminars in Oncology. 2010;37 Suppl 2:S2-S14.

10. Roodman GD. Cell biology of the osteoclast. Experimental Hematology. 1999;27(8):1229-1241.

11. Van Poznak C, Cross S, Saggese M, et al. Expression of osteoprotegerin (OPG), TNF related apoptosis inducing ligand (TRAIL), and receptor activator of nuclear factor kappaB ligand (RANKL) in human breast tumours. Journal of Clinical Pathology. 2006;59(1):56-63.

12. Yao GQ, Sun BH, Weir EC, Insogna KL. A role for cell-surface CSF-1 in osteoblast-mediated osteoclastogenesis. Calcified Tissue International. 2002;70(4):339-346.

13. Chambers AF, Groom AC, MacDonald IC. Dissemination and growth of cancer cells in metastatic sites. Nat Rev Cancer. 2002;2(8): 563-572.

14. Kang Y, Siegel PM, Shu W, et al. A multigenic program mediating breast cancer metastasis to bone. Cancer Cell. 2003;3(6):537-549.

15. Jezierska A, Motyl T. Matrix metalloproteinase-2 involvement in breast cancer progression: a mini-review. Med Sci Monit. 2009;15(2): RA32-RA40.

16. Nakopoulou L, Tsirmpa I, Alexandrou P, et al. MMP-2 protein in invasive breast cancer and the impact of MMP-2/TIMP-2 phenotype on overall survival. Breast Cancer Res Treat. 2003;77(2):145-155.

17. Ranuncolo SM, Armanasco E, Cresta C, Bal De Kier Joffe E, Puricelli L. Plasma MMP-9 (92 kDa-MMP) activity is useful in the follow-up and in the assessment of prognosis in breast cancer patients. International Journal of Cancer. 2003;106(5):745-751.

18. Raman D, Baugher PJ, Thu YM, Richmond A. Role of chemokines in tumor growth. Cancer Letters. 2007;256(2):137-165.

19. Campbell JJ, Butcher EC. Chemokines in tissue-specific and microenvironment-specific lymphocyte homing. Curr Opin Immunol. 2000;12(3):336-341.

20. Muller A, Homey B, Soto H, et al. Involvement of chemokine receptors in breast cancer metastasis. Nature. 2001;410(6824):50-56.

21. Cabioglu N, Sahin AA, Morandi P, et al. Chemokine receptors in advanced breast cancer: differential expression in metastatic disease sites with diagnostic and therapeutic implications. Annals of Oncology. 2009;20(6):1013-1019.

22. Rhodes LV, Short SP, Neel NF, et al. Cytokine receptor CXCR4 mediates estrogen-independent tumorigenesis, metastasis, and resistance to endocrine therapy in human breast cancer. Cancer Res. 2011;71(2): 603-613.

23. Liang Z, Yoon Y, Votaw J, Goodman MM, Williams L, Shim H. Silencing of CXCR4 blocks breast cancer metastasis. Cancer Res. 2005; 65(3):967-971.

24. Richert MM, Vaidya KS, Mills CN, et al. Inhibition of CXCR4 by CTCE-9908 inhibits breast cancer metastasis to lung and bone. Oncol Rep. 2009;21(3):761-767.
25. Hotte S, Hirte H, Moretto P. Final results of a Phase I/II study of CTCE-9908, a novel anticancer agent that inhibits CXCR4, in patients with advanced solid cancers [abstr 405], in EORTC/NCI/AACR Molecular Targets and Cancer Therapeutics 2008 conference. Eur J Cancer Suppl. 2008;6(12):127.

26. Soria G, Ben-Baruch A. The inflammatory chemokines CCL2 and CCL5 in breast cancer. Cancer Letters. 2008;267(2):271-285.

27. Karnoub AE, Dash AB, Vo AP, et al. Mesenchymal stem cells within tumour stroma promote breast cancer metastasis. Nature. 2007;449(7162):557-563.

28. Pinilla S, Alt E, Abdul Khalek FJ, et al. Tissue resident stem cells produce CCL5 under the influence of cancer cells and thereby promote breast cancer cell invasion. Cancer Letters. 2009;284(1):80-85.

29. Kahn D, Weiner GJ, Ben-Haim S, et al. Positron emission tomographic measurement of bone marrow blood flow to the pelvis and lumbar vertebrae in young normal adults.[erratum appears in Blood. 1994 Nov 15;84(10):3602]. Blood. 1994;83(4):958-963.

30. Paget $\mathrm{S}$. The distribution of secondary growths in cancer of the breast. Lancet. 1889;1:99-101.

31. Psaila B, Lyden D. The metastatic niche: adapting the foreign soil. Nat Rev Cancer. 2009;9(4):285-293.

32. Harvey HA. Issues concerning the role of chemotherapy and hormonal therapy of bone metastases from breast carcinoma. Cancer. 1997; 80(8 Suppl):1646-1651.

33. Coleman RE. Skeletal complications of malignancy. Cancer. 1997; 80(8 Suppl):1588-1594.

34. Powell GJ, Southby J, Danks JA, et al. Localization of parathyroid hormone-related protein in breast cancer metastases: increased incidence in bone compared with other sites. Cancer Res. 1991;51(11): 3059-3061.

35. Akhtari M, Mansuri J, Newman KA, Guise TM, Seth P. Biology of breast cancer bone metastasis. Cancer Biol Ther. 2008;7(1):3-9.

36. Kozlow W, Guise TA. Breast cancer metastasis to bone: mechanisms of osteolysis and implications for therapy. Journal of Mammary Gland Biology and Neoplasia. 2005;10(2):169-180.

37. Trinkaus M, Ooi WS, Amir E, et al. Examination of the mechanisms of osteolysis in patients with metastatic breast cancer. Oncol Rep. 2009; 21(5):1153-1159.

38. Kakonen SM, Selander KS, Chirgwin JM, et al. Transforming growth factor-beta stimulates parathyroid hormone-related protein and osteolytic metastases via Smad and mitogen-activated protein kinase signaling pathways. Journal of Biological Chemistry. 2002;277(27): 24571-24578.

39. Dunn LK, Mohammad KS, Fournier PG, et al. Hypoxia and TGF-beta drive breast cancer bone metastases through parallel signaling pathways in tumor cells and the bone microenvironment. PLoS One. 2009;4(9): e6896.

40. Kingsley LA, Fournier PG, Chirgwin JM, Guise TA. Molecular biology of bone metastasis. Mol Cancer Ther. 2007;6(10):2609-2617.

41. Guise TA, Yin JJ, Taylor SD, et al. Evidence for a causal role of parathyroid hormone-related protein in the pathogenesis of human breast cancer-mediated osteolysis. Journal of Clinical Investigation. 1996;98(7):1544-1549.

42. Guise TA, Mohammad KS, Clines G, et al. Basic mechanisms responsible for osteolytic and osteoblastic bone metastases. Clinical Cancer Research. 2006;12(20 Pt 2):6213s-6216s.

43. Clines GA, Guise TA. Molecular mechanisms and treatment of bone metastasis. Expert Reviews in Molecular Medicine. 2008;10:e7.

44. Clines GA, Mohammad KS, Bao Y, et al. Dickkopf homolog 1 mediates endothelin-1-stimulated new bone formation. Molecular Endocrinology. 2007;21(2):486-498.

45. Hall CL, Bafico A, Dai J, Aaronson SA, Keller ET. Prostate cancer cells promote osteoblastic bone metastases through Wnts. Cancer Res. 2005;65(17):7554-7560.

46. Bussard KM, Venzon DJ, Mastro AM. Osteoblasts are a major source of inflammatory cytokines in the tumor microenvironment of bone metastatic breast cancer. J Cell Biochem. 2010;111(5): 1138-1148. 
47. Guise TA, Yin JJ, Mohammad KS. Role of endothelin-1 in osteoblastic bone metastases. Cancer. 2003;97(3 Suppl):779-784.

48. Body JJ. Breast cancer: bisphosphonate therapy for metastatic bone disease. Clinical Cancer Research. 2006;12(20 Pt 2):6258s-6263s.

49. Chen T, Berenson J, Vescio R, et al. Pharmacokinetics and pharmacodynamics of zoledronic acid in cancer patients with bone metastases. Journal of Clinical Pharmacology. 2002;42(11):1228-1236.

50. Masarachia P, Weinreb M, Balena R, Rodan GA. Comparison of the distribution of $3 \mathrm{H}$-alendronate and $3 \mathrm{H}$-etidronate in rat and mouse bones. Bone. 1996;19(3):281-290.

51. Rogers MJ. New insights into the molecular mechanisms of action of bisphosphonates. Current Pharmaceutical Design. 2003;9(32): 2643-2658.

52. Roelofs AJ, Thompson K, Gordon S, Rogers MJ. Molecular mechanisms of action of bisphosphonates: current status. Clinical Cancer Research 2006;12(20 Pt 2):6222s-6230s.

53. Pavlakis N, Schmidt R, Stockler M. Bisphosphonates for breast cancer. Cochrane Database of Systematic Reviews. 2005;3:CD003474.

54. Theriault RL, Lipton A, Hortobagyi GN, et al. Pamidronate reduces skeletal morbidity in women with advanced breast cancer and lytic bone lesions: a randomized, placebo-controlled trial. Protocol 18 Aredia Breast Cancer Study Group. Journal of Clinical Oncology. 1999;17(3):846-854.

55. Lipton A, Theriault RL, Hortobagyi GN, et al. Pamidronate prevents skeletal complications and is effective palliative treatment in women with breast carcinoma and osteolytic bone metastases: long term follow-up of two randomized, placebo-controlled trials. Cancer. 2000; 88(5):1082-1090.

56. Body JJ, Diel IJ, Bell R, et al. Oral ibandronate reduces the risk of skeletal complications in breast cancer patients with metastatic bone disease: results from two randomised, placebo-controlled phase III studies. British Journal of Cancer. 2004;90(6):1133-1137.

57. Tripathy D, Lichinitzer M, Lazarev A, et al. Oral ibandronate for the treatment of metastatic bone disease in breast cancer: efficacy and safety results from a randomized, double-blind, placebo-controlled trial.[see comment]. Annals of Oncology. 2004;15(5):743-750.

58. Cook RJ, Major P. Methodology for treatment evaluation in patients with cancer metastatic to bone.[see comment]. Journal of the National Cancer Institute. 2001;93(7):534-538

59. Body JJ. Treatment and prevention of bone metastases and myeloma bone disease. 6th ed. Primer on the metabolic bone diseases and disorders of minderal metabolism. American Soceity for Bone and Mineral Research; 2006.

60. Rosen LS, Gordon D, Kaminski M, et al. Zoledronic acid versus pamidronate in the treatment of skeletal metastases in patients with breast cancer or osteolytic lesions of multiple myeloma: a phase III, double-blind, comparative trial.[see comment]. Cancer Journal. 2001;7(5):377-387.

61. Rosen LS, Gordon DH, Dugan W Jr, et al. Zoledronic acid is superior to pamidronate for the treatment of bone metastases in breast carcinoma patients with at least one osteolytic lesion. Cancer. 2004; 100(1):36-43.

62. Body JJ, Lichinitser M, Tjulandin S, Garnero P, Bergstrom B. Oral ibandronate is as active as intravenous zoledronic acid for reducing bone turnover markers in women with breast cancer and bone metastases. [see comment][erratum appears in Ann Oncol. 2008 Mar;19(3):601]. Annals of Oncology. 2007;18(7):1165-1171.

63. NationalInstituteofHealth.ClinicalTrials.gov. 2011. [updated 24/10/09]; http://clinicaltrials.gov/ct2/info/about. Accessed 27/02/11.

64. Kaminski M, Rosen L, Gordon D, Zheng M, Hei YJ. Zoledronic acid versus pamidronate in patients with breast cancer and multiple myeloma who are at high risk for skeletal complications [abstract 857]. Proc Am Soc Clin Oncol. 2004;22(14S):90.

65. Hillner BE, Ingle JN, Chlebowski RT, Gralow J, Yee GC, et al. American Society of Clinical Oncology 2003 update on the role of bisphosphonates and bone health issues in women with breast cancer.[erratum appears in J Clin Oncol. 2004 Apr 1;22(7):1351 Note: Dosage error in article text]. Journal of Clinical Oncology. 2003;21(21):4042-4057.
66. Aapro M, Abrahamsson PA, Body JJ, et al. Guidance on the use of bisphosphonates in solid tumours: recommendations of an international expert panel. Annals of Oncology. 2008;19(3):420-432.

67. Body JJ, Mancini I. Bisphosphonates for cancer patients: why, how, and when? Supportive Care in Cancer. 2002;10(5):399-407.

68. Woo SB, Hellstein JW, Kalmar JR. Narrative [corrected] review: bisphosphonates and osteonecrosis of the jaws. Ann Intern Med. 2006;144(10):753-761.

69. Hamaoka T, Madewell JE, Podoloff DA, Hortobagyi GN, Ueno NT. Bone imaging in metastatic breast cancer.[see comment]. Journal of Clinical Oncology. 2004;22(14):2942-2953.

70. Van Poznak CH, Temin S, Yee GC, et al. American Society of Clinical Oncology Executive Summary of the Clinical Practice Guideline Update on the Role of Bone-Modifying Agents in Metastatic Breast Cancer. Journal of Clinical Oncology. 2011.

71. Diel IJ. Effectiveness of bisphosphonates on bone pain and quality of life in breast cancer patients with metastatic bone disease: a review. Supportive Care in Cancer. 2007;15(11):1243-1249.

72. ClinicalPracticeCommittee. Hypercalcemia in malignant disease. Hospice Palliative Care Program: Symptom Guidelines 2006. [cited 24/11/06]. Available from: http://www.fraserhealth.ca/professionals/ resources/hospice_palliative_care/hospice_palliative_care_symptom_ guidelines. Accessed 20/12/10.

73. MIMSAustralia. MIMS Full Prescribing Information. In: Donohoo E, editor. Sydney. MIMS Australia. 2009.

74. Powles T, Paterson S, Kanis JA, et al. Randomized, placebo-controlled trial of clodronate in patients with primary operable breast cancer.[see comment]. Journal of Clinical Oncology. 2002;20(15):3219-3224.

75. Body JJ, Diel IJ, Bell R, et al. Intravenous ibandronate reduces the incidence of skeletal complications in patients with breast cancer and bone metastases.[see comment]. Annals of Oncology. 2003;14(9):1399-1405.

76. Lipton A. Denosumab in Breast Cancer. Curr Oncol Rep. 2010 13(1):1-4.

77. Fizazi K, Lipton A, Mariette X, et al. Randomized phase II trial of denosumab in patients with bone metastases from prostate cancer, breast cancer, or other neoplasms after intravenous bisphosphonates.[see comment]. Journal of Clinical Oncology. 2009;27(10): $1564-1571$.

78. Stopeck AT, Lipton A, Body JJ, et al. Denosumab compared with zoledronic Acid for the treatment of bone metastases in patients with advanced breast cancer: a randomized, double-blind study. Journal of Clinical Oncology. 2010;28(35):5132-5139.

79. Coleman RE. Metastatic bone disease: clinical features, pathophysiology and treatment strategies. Cancer Treatment Reviews. 2001;27(3): 165-176.

80. Meuser T, Pietruck C, Radbruch L, Stute P, Lehmann KA, Grond S. Symptoms during cancer pain treatment following WHO-guidelines: a longitudinal follow-up study of symptom prevalence, severity and etiology. Pain. 2001;93(3):247-257.

81. Goblirsch MJ, Zwolak PP, Clohisy DR. Biology of bone cancer pain. Clinical Cancer Research. 2006;12(20 Pt 2):6231s-6235s.

82. Woodruff R. Symptom control in advanced cancer. 2nd ed. 2002, Melbourne: Asperula Pty Ltd.

83. Cleeland CS. The measurement of pain from metastatic bone disease: capturing the patient's experience. Clinical Cancer Research. 2006;12(20 Pt 2):6236s-6242s.

84. Wong R, Wiffen PJ. Bisphosphonates for the relief of pain secondary to bone metastases. Cochrane Database of Systematic Reviews. 2002;2:CD002068.

85. Clemons MJ, Dranitsaris G, Ooi WS, et al. Phase II trial evaluating the palliative benefit of second-line zoledronic acid in breast cancer patients with either a skeletal-related event or progressive bone metastases despite first-line bisphosphonate therapy. Journal of Clinical Oncology. 2006;24(30):4895-4900.

86. Body JJ, Diel IJ, Bell R, et al. Oral ibandronate improves bone pain and preserves quality of life in patients with skeletal metastases due to breast cancer. Pain. 2004;111(3):306-312. 
87. Diel IJ, Body JJ, Lichinitser MR, et al. Improved quality of life after long-term treatment with the bisphosphonate ibandronate in patients with metastatic bone disease due to breast cancer. European Journal of Cancer. 2004;40(11):1704-1712.

88. Hoskin PJ. Bisphosphonates and radiation therapy for palliation of metastatic bone disease. Cancer Treatment Reviews. 2003;29(4): 321-327.

89. Chow E, Harris K, Fan G, Tsao M, Sze WM. Palliative radiotherapy trials for bone metastases: a systematic review. Journal of Clinical Oncology. 2007;25(11):1423-1436.

90. Chow E, Makhani L, Culleton S, et al. Would larger radiation fields lead to a faster onset of pain relief in the palliation of bone metastases? International Journal of Radiation Oncology Biology Physics. 2009;74(5):1563-1566.

91. Ural AU, Avcu F, Baran Y. Bisphosphonate treatment and radiotherapy in metastatic breast cancer. Medical Oncology. 2008;25(3): 350-355.

92. Fairchild A, Chow E. Role of radiation therapy and radiopharmaceuticals in bone metastases. Curr Opin Support Palliat Care. 2007;1(3): 169-173.

93. Bauman G, Charette M, Reid R, Sathya J. Radiopharmaceuticals for the palliation of painful bone metastasis-a systemic review. Radiotherapy and Oncology. 2005;75(3):258-270.

94. Baczyk M, Czepczynski R, Milecki P, Pisarek M, Oleksa R, Sowinski J. 89Sr versus 153Sm-EDTMP: comparison of treatment efficacy of painful bone metastases in prostate and breast carcinoma. Nuclear Medicine Communications. 2007;28(4):245-250.

95. Plunkett TA, Smith P, Rubens RD. Risk of complications from bone metastases in breast cancer. implications for management. European Journal of Cancer. 2000;36(4):476-482.

96. Hill ME, Richards MA, Gregory WM, Smith P, Rubens RD. Spinal cord compression in breast cancer: a review of 70 cases. British Journal of Cancer. 1993;68(5):969-973.

97. Patchell RA, Tibbs PA, Regine WF, et al. Direct decompressive surgical resection in the treatment of spinal cord compression caused by metastatic cancer: a randomised trial.[see comment]. Lancet. 2005;366(9486):643-648.

98. Nabholtz JM, Falkson C, Campos D, et al. Docetaxel and doxorubicin compared with doxorubicin and cyclophosphamide as first-line chemotherapy for metastatic breast cancer: results of a randomized, multicenter, phase III trial. Journal of Clinical Oncology. 2003;21(6): 968-975.

99. Sledge GW, Neuberg D, Bernardo P, et al. Phase III trial of doxorubicin, paclitaxel, and the combination of doxorubicin and paclitaxel as front-line chemotherapy for metastatic breast cancer: an intergroup trial (E1193). Journal of Clinical Oncology. 2003;21(4):588-592.

100. Gradishar WJ, Tjulandin S, Davidson N, et al. Phase III trial of nanoparticle albumin-bound paclitaxel compared with polyethylated castor oil-based paclitaxel in women with breast cancer. Journal of Clinical Oncology. 2005;23(31):7794-7803.

101. O’Shaughnessy J, Miles D, Vukelja S, et al. Superior survival with capecitabine plus docetaxel combination therapy in anthracyclinepretreated patients with advanced breast cancer: phase III trial results. Journal of Clinical Oncology. 2002;20(12):2812-2823.

102. Keller AM, Mennel RG, Georgoulias VA, et al. Randomized phase III trial of pegylated liposomal doxorubicin versus vinorelbine or mitomycin $\mathrm{C}$ plus vinblastine in women with taxane-refractory advanced breast cancer. Journal of Clinical Oncology. 2004;22(19):3893-3901.

103. Sparano JA, Vrdoljak E, Rixe O, et al. Randomized phase III trial of ixabepilone plus capecitabine versus capecitabine in patients with metastatic breast cancer previously treated with an anthracycline and a taxane. Journal of Clinical Oncology. 2010;28(20):3256-3263.

104. Hess KR, Pusztai L, Buzdar AU, Hortobagyi GN. Estrogen receptors and distinct patterns of breast cancer relapse. Breast Cancer Res Treat. 2003;78(1):105-118.

105. Smid M, Wang Y, Zhang Y, et al. Subtypes of breast cancer show preferential site of relapse. Cancer Res. 2008;68(9):3108-3114.
106. McCafferty MP, McNeill RE, Miller N, Kerin MJ. Interactions between the estrogen receptor, its cofactors and microRNAs in breast cancer. Breast Cancer Res Treat. 2009;116(3):425-432.

107. Gibson L, Lawrence D, Dawson C, Bliss J. Aromatase inhibitors for treatment of advanced breast cancer in postmenopausal women. Cochrane Database of Systematic Reviews. 2009;4:CD003370.

108. Kaufmann M, Bajetta E, Dirix LY, et al. Exemestane is superior to megestrol acetate after tamoxifen failure in postmenopausal women with advanced breast cancer: results of a phase III randomized double-blind trial. The Exemestane Study Group. Journal of Clinical Oncology. 2000;18(7):1399-1411.

109. Dombernowsky P, Smith I, Falkson G, et al. Letrozole, a new oral aromatase inhibitor for advanced breast cancer: double-blind randomized trial showing a dose effect and improved efficacy and tolerability compared with megestrol acetate. Journal of Clinical Oncology. 1998;16(2):453-461.

110. Buzdar A, Douma J, Davidson N, et al. Phase III, multicenter, doubleblind, randomized study of letrozole, an aromatase inhibitor, for advanced breast cancer versus megestrol acetate. Journal of Clinical Oncology. 2001;19(14):3357-3366.

111. Rose C, Vtoraya O, Pluzanska A, et al. An open randomised trial of second-line endocrine therapy in advanced breast cancer. comparison of the aromatase inhibitors letrozole and anastrozole. Eur J Cancer. 2003;39(16):2318-2327.

112. Osborne CK, Pippen J, Jones SE, et al. Double-blind, randomized trial comparing the efficacy and tolerability of fulvestrant versus anastrozole in postmenopausal women with advanced breast cancer progressing on prior endocrine therapy: results of a North American trial. Journal of Clinical Oncology. 2002;20(16):3386-3395.

113. Howell A, Pippen J, Elledge RM, et al. Fulvestrant versus anastrozole for the treatment of advanced breast carcinoma: a prospectively planned combined survival analysis of two multicenter trials. Cancer. 2005;104(2):236-239.

114. Shannon C, Bassanelli D, De Boer R, McCarthy E, Rice J, Yates P. Recommendations for use of endocrine therapy for the treatment of hormone receptor-positive advanced breast cancer. NBOCC: NSW; 2008.

115. Beslija S, Bonneterre J, Burstein HJ, et al. Third consensus on medical treatment of metastatic breast cancer. Annals of Oncology. 2009;20(11):1771-1785.

116. Guarneri V, Conte P. Metastatic breast cancer: therapeutic options according to molecular subtypes and prior adjuvant therapy. Oncologist. 2009;14(7):645-656.

117. Winter MC, Holen I, Coleman RE. Exploring the anti-tumour activity of bisphosphonates in early breast cancer. Cancer Treatment Reviews. 2008;34(5):453-475.

118. Mundy GR, Yoneda T, Hiraga T. Preclinical studies with zoledronic acid and other bisphosphonates: impact on the bone microenvironment. Seminars in Oncology. 2001;28(2 Suppl 6):35-44.

119. Hiraga T, Williams PJ, Ueda A, Tamura D, Yoneda T. Zoledronic acid inhibits visceral metastases in the 4T1/luc mouse breast cancer model. Clinical Cancer Research. 2004;10(13):4559-4567.

120. Santini D, Martini F, Fratto ME, et al. In vivo effects of zoledronic acid on peripheral gammadelta $\mathrm{T}$ lymphocytes in early breast cancer patients. Cancer Immunology Immunotherapy. 2009;58(1):31-38.

121. Neville-Webbe HL, Rostami-Hodjegan A, Evans CA, Coleman RE, Holen I. Sequence- and schedule-dependent enhancement of zoledronic acid induced apoptosis by doxorubicin in breast and prostate cancer cells. International Journal of Cancer. 2005;113(3): 364-371.

122. Diel IJ, Solomayer EF, Costa SD, et al. Reduction in new metastases in breast cancer with adjuvant clodronate treatment.[see comment]. New England Journal of Medicine. 1998;339(6):357-363.

123. Saarto T, Vehmanen L, Virkkunen P, Blomqvist C. Ten-year follow-up of a randomized controlled trial of adjuvant clodronate treatment in node-positive breast cancer patients. Acta Oncol. 2004; 43(7):650-656. 
124. Diel LJ, Jaschke A, Solomayer EF, et al. Adjuvant oral clodronate improves the overall survival of primary breast cancer patients with micrometastases to the bone marrow - A long-term follow-up. Annals of Oncology. 2008;19(12):2007-2011.

125. Powles T, Paterson A, McCloskey E, et al. Reduction in bone relapse and improved survival with oral clodronate for adjuvant treatment of operable breast cancer [ISRCTN83688026].[erratum appears in Breast Cancer Res. 2006;8(3):406]. Breast Cancer Research. 2006; $8(2):$ R13

126. Saarto T, Blomqvist C, Virkkunen P, Elomaa I. Adjuvant clodronate treatment does not reduce the frequency of skeletal metastases in node-positive breast cancer patients: 5-year results of a randomized controlled trial. Journal of Clinical Oncology. 2001;19(1):10-17.

127. Ha TC, Li H. Meta-analysis of clodronate and breast cancer survival. British Journal of Cancer. 2007;96(12):1796-1801.

128. Gnant M, Mlineritsch B, Schippinger W, et al. Endocrine therapy plus zoledronic acid in premenopausal breast cancer. New England Journal of Medicine. 2009;360(7):679-691.

129. Coleman RE. Adjuvant bisphosphonates in breast cancer: are we witnessing the emergence of a new therapeutic strategy? European Journal of Cancer. 2009;45(11):1909-1915.

130. Gnant M, Mlineritsch B, Luschin-Ebengreuth G, et al. Adjuvant endocrine therapy plus zoledronic acid in premenopausal women with early-stage breast cancer: 5-year follow-up of the ABCSG-12 bonemineral density substudy. Lancet Oncology. 2008;9(9):840-849.

131. Eidtmann H, de Boer R, Bundred N, et al. Efficacy of zoledronic acid in postmenopausal women with early breast cancer receiving adjuvant letrozole: 36-month results of the ZO-FAST Study. Annals of Oncology. 2010;21(11):2188-2194.

132. Brufsky AM, Bosserman LD, Caradonna RR, et al. Zoledronic acid effectively prevents aromatase inhibitor-associated bone loss in postmenopausal women with early breast cancer receiving adjuvant letrozole: Z-FAST study 36-month follow-up results. Clin Breast Cancer. 2009;9(2):77-85.

133. Brufsky A, Bundred N, Coleman R, et al. Integrated analysis of zoledronic acid for prevention of aromatase inhibitor-associated bone loss in postmenopausal women with early breast cancer receiving adjuvant letrozole. Oncologist. 2008;13(5):503-514.

134. Winter M, Thorpe H, Burkinshaw R, Beevers SJ, Coleman RE The addition of zoledronic acid to neoadjuvant chemotherapy may influence pathological response - exploratory evidence for direct anti-tumor activity in breast cancer. Cancer Research. 2009; 69(2 Suppl):Abstract 5101.

135. Coleman RE, Thorpe HC, Cameron D, et al. Adjuvant Treatment with Zoledronic Acid in Stage II/III Breast Cancer. The AZURE Trial (BIG 01/04). in 33rd Annual San Antonio Breast Cancer Symposium. San Antonio; 2010.

136. Chustecka Z. AZURE: Zolendronic Acid Effect on Breast Cancer Is Complicated; 33rd Annual San Antonio Breast Cancer Symposium (SABCS). Medscape news 2010. [updated 10/12/10]; http:/www. medscape.com/viewarticle/733978. Accessed 10/11/11.

137. Jensen AO, Jacobsen JB, Norgaard M, Yong M, Fryzek JP, Sorensen HT. Incidence of bone metastases and skeletal-related events in breast cancer patients: A population-based cohort study in Denmark. BMC Cancer. 2011;11:29.

138. Rose AA, Siegel PM. Emerging therapeutic targets in breast cancer bone metastasis. Future Oncol. 2010;6(1):55-74.

139. Lipton A. Denosumab in breast cancer. Curr Oncol Rep. 2010;13(1): $1-4$.

140. Fizazi K, Carducci M, Smith M, et al. Denosumab versus zoledronic acid for treatment of bone metastases in men with castrationresistant prostate cancer: a randomised, double-blind study. The Lancet Published Online February 25;2011 DOI:10.1016/S01406736(10)62344-62011. [cited. Accessed February 25, 2011.

141. Padua D, Zhang XH, Wang Q, et al. TGFbeta primes breast tumors for lung metastasis seeding through angiopoietin-like 4. Cell. 2008; 133(1):66-77.
142. Petersen M, Pardali E, van der Horst G, et al. Smad2 and Smad3 have opposing roles in breast cancer bone metastasis by differentially affecting tumor angiogenesis. Oncogene. 2010;29(9):1351-1361.

143. Tan AR, Alexe G, Reiss M. Transforming growth factor-beta signaling: emerging stem cell target in metastatic breast cancer? Breast Cancer Research and Treatment. 2009;115(3):453-495.

144. Di Cosimo S, Baselga J. Targeted therapies in breast cancer: where are we now? Eur J Cancer. 2008;44(18):2781-2790.

145. Hiscox S, Barrett-Lee P, Borley AC, Nicholson RI. Combining Src inhibitors and aromatase inhibitors: a novel strategy for overcoming endocrine resistance and bone loss. Eur J Cancer. 2010;46(12): 2187-2195

146. Kleer CG, Bloushtain-Qimron N, Chen YH, et al. Epithelial and stromal cathepsin $\mathrm{K}$ and CXCL14 expression in breast tumor progression. Clinical Cancer Research. 2008;14(17):5357-5367.

147. Jensen AB, Olmeo N, Wynne C, et al. Effect of cathepsin k inhibition on suppression of bone resorption in women with breast cancer and established bone metastases in a 4-week, double-blind, randomized controlled trial. J Clin Oncol. 2008 May;20 Suppl:Abstr 4508.

148. Wong D, Korz W. Translating an Antagonist of Chemokine Receptor CXCR4: from bench to bedside. Clinical Cancer Research. 2008; 14(24):7975-7980.

149. Lipton A. Future treatment of bone metastases. Clinical Cancer Research. 2006;12(20 Pt 2):6305s-6308s.

150. Strube A, Hoffmann J, Stepina E, Hauff P, Klar U, Kakonen SM. Sagopilone inhibits breast cancer bone metastasis and bone destruction due to simultaneous inhibition of both tumor growth and bone resorption. Clinical Cancer Research. 2009;15(11):3751-3759.

151. Bohn OL, Nasir I, Brufsky A, et al. Biomarker profile in breast carcinomas presenting with bone metastasis. Int J Clin Exp Pathol. 2010;3(2):139-146.

152. Woelfle U, Cloos J, Sauter G, et al. Molecular signature associated with bone marrow micrometastasis in human breast cancer. Cancer Res. 2003;63(18):5679-5684.

153. Smid M, Wang Y, Klijn JG, et al. Genes associated with breast cancer metastatic to bone.[see comment]. Journal of Clinical Oncology. 2006;24(15):2261-2267.

154. Gast MC, Schellens JH, Beijnen JH. Clinical proteomics in breast cancer: a review. Breast Cancer Res Treat. 2009;116(1):17-29.

155. Harris L, Fritsche H, Mennel R, et al. American Society of Clinical Oncology 2007 update of recommendations for the use of tumor markers in breast cancer. Journal of Clinical Oncology. 2007;25(33):5287-5312.

156. Brown JE, Cook RJ, Lipton A, Costa L, Coleman RE. Prognostic factors for skeletal complications from metastatic bone disease in breast cancer. Breast Cancer Res Treat. 2010;123(3):767-779.

157. Clemons M, Dranitsaris G, Cole D, Gainford MC. Too much, too little, too late to start again? Assessing the efficacy of bisphosphonates in patients with bone metastases from breast cancer. Oncologist 2006;11(3):227-233.

158. Brown JE, Thomson CS, Ellis SP, Gutcher SA, Purohit OP, Coleman RE. Bone resorption predicts for skeletal complications in metastatic bone disease. British Journal of Cancer. 2003;89(11):2031-2037.

159. Coleman RE, Major P, Lipton A, et al. Predictive value of bone resorption and formation markers in cancer patients with bone metastases receiving the bisphosphonate zoledronic acid. Journal of Clinical Oncology. 2005;23(22):4925-4935.

160. Lipton A. Biochemical bone markers in breast cancer. Cancer Treatment Reviews. 2006;32 Suppl 1:20-22.

161. Lopez-Carrizosa MC, Samper-Ots PM, Perez AR. Serum C-telopeptide levels predict the incidence of skeletal-related events in cancer patients with secondary bone metastases. Clin Transl Oncol. 2010; 12(8):568-573.

162. Carlson R, Anderson B, Burstein H, et al. Breast Cancer. NCCN Clinical Practice Guidelines in Oncology 2011. [cited 5/1/11]. Available from: http://www.nccn.org/professionals/physician_gls/f_ guidelines.asp. Accessed 25/2/11. 
163. Khatcheressian JL, Wolff AC, Smith TJ, et al. American Society of Clinical Oncology 2006 update of the breast cancer follow-up and management guidelines in the adjuvant setting. Journal of Clinical Oncology. 2006;24(31):5091-5097.

164. Rojas MP, Telaro E, Russo A, et al. Follow-up strategies for women treated for early breast cancer.[update of Cochrane Database Syst Rev. 2000;4:CD001768; PMID: 11034727]. Cochrane Database of Systematic Reviews. 2005;1:CD001768.

165. Marguiles AG, Klimberg VS, Bhattacharrya S, Gaddy D, Suva LJ. Genomics and proteomics of bone cancer. Clinical Cancer Research. 2006;12(20):6217s-6221s
166. Fateh-Moghadam A, Stieber P. Sensible use of tumour markers. Munich: Jurgen Hartmann Verlag GmbH; 1993.

167. Siemionow K, Lieberman IH. Vertebral augmentation in osteoporosis and bone metastasis. Current Opinion in Supportive and Palliative Care. 2007;1(4):323-327.

168. Saad F. Optimizing patient therapy: the role of bone markers? Cancer Treatment Reviews. 2006;32 Suppl 1:3-6.

169. Brufsky A, Bundred N, Coleman R, et al. Integrated analysis of zoledronic acid for prevention of aromatase inhibitor-associated bone loss in postmenopausal women with early breast cancer receiving adjuvant letrozole. Oncologist. 2008;13(5):503-514.

\section{Publish your work in this journal}

Breast Cancer: Targets and Therapy is an international, peerreviewed open access journal focusing on breast cancer research, identification of therapeutic targets and the optimal use of preventative and integrated treatment interventions to achieve improved outcomes, enhanced survival and quality of life for the cancer patient.
View the full aims and scopes of this journal here. The manuscript management system is completely online and includes a very quick and fair peer-review system, which is all easy to use. Visit http:// www.dovepress.com/testimonials.php to read real quotes from published authors.

Submit your manuscript here: http://www.dovepress.com/breast-cancer---targets-and-therapy-journal 